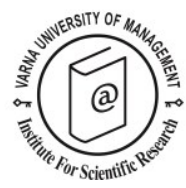

\title{
Nature sports participation: Understanding demand, practice profile, motivations and constraints
}

\author{
Ricardo Melo ${ }^{1 *}$ and Rui Gomes²
}

Received: 15/06/2015 Accepted: 21/11/2016

\begin{abstract}
1 Polytechnic Institute of Coimbra, Coimbra Education School, ASSERT, IRNIST, Rua Dom João III, Solum, 3030-329 Coimbra, Portugal; Phone: 00351239793 120; E-mail: ricardo.es.melo@gmail.com

${ }^{2}$ Centre for Social Studies, University of Coimbra, Portugal; E-mail: ramgomes@gmail.com

* Corresponding author
\end{abstract}

\begin{abstract}
Nature sports is a sports field associated with active sport tourism and is one of the fastest growing segments of the tourism industry. Even though nature sports are economically very significant, little is known about participants and their participatory behaviour. Thus, a study was conducted using a convenient sample of 1126 nature sports participants to understand their socio-demographic characteristics, demand profile, practice behaviours, motivations and constraints. The results indicate that nature sports participants are mainly young males, with higher education, highlyqualified jobs and high income. The nature sports activity that most of the surveyed individuals already practice is MTB. This is also the activity practiced more frequently by more individuals, and the activity most individuals would like to practice more often. Nature and adventure are indicated as the main reasons for practicing nature sports, while lack of time and lack of money are the main constraints for participation. Statistical tests also revealed significant statistical differences in participation between the different nature sports activities. These data allow augmenting the management and marketing intelligence for owners and managers of nature sports-related businesses as well as agencies and organizations promoting nature sports (tourism). Policy implications for nature sports are also discussed.
\end{abstract}

(C) 2017 Varna University of Management. All rights reserved

Keywords: constraints, demand, motivations, nature sports, participation, sport tourism.

Citation: Melo, R., R. Gomes (2017) Nature sports participation: Understanding demand, practice profile, motivations and constraints. European Journal of Tourism Research, 16, pp. 108-135

\section{Introduction}

Nature sports is an expression that has emerged in the recent years as a sports field that is related to the leisure and tourism industries. It is a concept associated with the values of a trans-modern society (Corneloup,
2011). Nature sports comprise a group of sporting activities that are developed and experienced in natural or rural areas, ranging from formal to informal practices, and which may contribute to sustainable local development (Melo \& Gomes, 2017). These 
practices are performed in different natural contexts including in the air (paragliding and hang-gliding, etc.), on land (MTB, rockclimbing, trekking, etc.) and in water (kayaking, sailing, surfing, windsurfing, etc.).

According to Bessy and Mouton (2004), the nature sports designation only arose in the late $20^{\text {th }}$ century, and was associated with the emergence of new sports venues in nature and the increased number of participants taking part in a set of social and structural practices. Melo and Gomes (2017) highlight three factors in the evolution of this concept: a) a new sports context that enabled a sports diffusion process in society, by offering multiple opportunities for developing sports activities; b) the emergence of the concept of sustainable development, which attributes a major role in sports activities to local economic development and the structuring of these activities; and c) the commodification of nature activities, through labels (products) which are related to adventure and particularly with ecology.

Natural places and nature sports are clearly major components of tourism (Hall \& Page, 2006; Weiler \& Hall, 1992). The relationship between nature sports and sport tourism is evident from the fact that a significant number of these sports are developed in places located at a distance from practitioners' home, meaning that travel and tourism are required, often to natural places and rural zones. This generates economic impact in the touristic/tourism destinations (Melo \& Gomes, 2016a; 2016b). Sport tourism is a term that has been adopted in recent years to describe leisure travel that is related to sport (Gibson, 1998b; Melo \& Sorby, 2017; Pigeassou, 2004). Sport tourism is “(...) leisure-based travel that takes individuals temporarily outside of their home communities to participate in physical activities, to watch physical activities, or to venerate attractions associated with physical activities" (Gibson, 1998 b, p. 49). Active participation in nature sports is directly associated with active sport tourism, which is one of the three major components of sport tourism (Gibson, 1998a) and can be divided into three types of travel (De Knop, 1990): a) the pure sport holiday, such as a trip to go skiing; b) taking advantage of the sports facilities at a holiday destination, though sport is not the primary purpose of the trip and; c) the private sporting holiday, where tourists take part in non-organized sport activities such as snorkelling, kayaking, MTB, and so on.

The importance of the sport tourism segment, and nature sports in particular, is evidenced by the growing attention given to it by the tourism and sports industries and by the development of a range of academic works (Gibson, 2005), demonstrating an expansive and significant area of mutual interest between sports management and tourism development (Hinch \& Higham, 2004). In this regard, the naturebased tourism market, which includes soft (e.g., trekking) and hard nature sports (e.g., rafting, kayaking and hiking), is often presented as the fastest growing segment within the tourism industry, with an increase of between $10 \%$ and $30 \%$ per year (Balmford, et al., 2009; Bell, Tyrvainen, Sievanen, Prbstl, \& Simpson, 2007; Marques, Reis, \& Menezes, 2010; Mehmetoglu, 2007). Further, it is estimated that $10 \%$ to $20 \%$ of all global international travels are, directly or indirectly, related to the enjoyment of and interaction with nature (Centre for Responsible Travel, 2015). However, estimations and figures should be interpreted with caution because, although valuable, many of them are in fact approximations and are rarely supported by consistent statistics targeted to measure specific features of nature-based tourism (Balmford et al., 2009; Barić, Anić, \& Macías Bedoya, 2016; Page \& Dowling, 2002).

Even though nature sports are economically very significant, few studies have examined this segment of sport tourism. Aiming to fill such a gap in the literature, a study was undertaken to understand nature sports participation. Specifically, this article addresses three objectives: 1) to understand the sociodemographic characteristics, demand profile, practice behaviours, motivations and constraints of nature sports participants; 2) to explore whether socio-demographic characteristics influence demand profile, practice behaviour, motivations and constraints for participating in nature sports activities; 3 ) to examine whether and to what extent different nature sports activities influence the practice 
behaviour, motivations and constraints of participating in nature sports activities.

\section{Examining nature sports participation} augments the marketing intelligence for owners and managers of nature sports based businesses (e.g., sport tourism companies, tour operators, and nature sports schools) as well as agencies and organizations promoting nature sports (tourism). This information can be critical given the size of the global nature tourism industry and its economic significance. For example, identifying the socio-demographics, practice behaviour and motivations of participants means that these aspects can be utilized to craft promotional messages that target certain categories of nature sports participants. On other hand, understanding the constraints of nature sports can allow managers to develop an adequate policy that promotes nature sports to all segments of the population and eliminates asymmetries in nature sports participation.

The following sections review the literature related to nature sports participation, detailing motivation and constraints. The remaining sections detail the study methods, results and conclusions.

\section{Literature review}

Nature sports participation

Understanding participation is currently one of the most debated and complex themes of sport tourism and nature sports (Melo, 2017). Existing literature covering sport tourism has examined participation through the development of several frameworks that can be applied to nature sports, namely, typologies of sport tourism (Gammon \& Robinson, 1997; Standeven \& De Knop, 1999) and the classification of sport tourism activities into active and passive forms (Gibson, 1998a; Hall, 1992). Later, Jackson and Weed (2003) developed the Sports Tourism Demand Continuum, while Weed and Bull (2004) proposed a Sport Tourism Participation Model. Despite the very important contributions of these frameworks to understanding sport tourism participation, there is also a need to move into explanation of participation and nonparticipation (Melo, 2017). In doing this, it is important to integrate concepts from the wider fields of leisure, tourism and sport studies, to understand the influence of some participation determinants (e.g., age, gender, social class, disability, etc.) (Gibson, 2002).

Generally, the knowledge produced about sport tourism and, more specifically about nature sports participation, is increasingly constituted by employing a multi-disciplinary of perspective (Weed, 2006), within the different social sciences: sociology, psychology, geography, and philosophy (Melo, 2017).

Focusing on the main concepts of culture from the sociology of culture and developments of cultural anthropology, Pociello (1995) presented three different perspectives of the concept of sports cultures, applied to the (nature) sports field: a restricted sociological perspective; a less restrictive sociological perspective; and a wider sociological perspective. In the restricted sociological perspective, the notion of culture must be understood as a distinctive property of class, within a hierarchical and stratified society. From a less restrictive sociological perspective, culture should be understood as the organization, transmission or reproduction of the practices and symbolic products of any social group, without pre-judging the nature of their relationship or their subjugation. On the other hand, from a wider sociological perspective, culture can adopt an anthropological sense which describes a structured group of practices, tools and techniques, the standards of industry, culture and habitat, the types of customs, beliefs and myths, as well as the traditional and recreational uses of the body that are characteristic of a society and a unified and coherent world view.

In the early 1980s, the serious leisure perspective was introduced by Stebbins (1982), as a framework for research about participation in leisure. This was used to understand nature sports participation, amongst, for example, climbers (Dilley \& Scraton, 2010); climbers, kayakers and snowboarders (Stebbins, 2005); mountain bikers (Getz \& McConnell, 2011); surfers (Barbieri \& Sotomayor, 2013; Cheng \& Tsaur, 2012; Portugal, Campos, Martins, \& Melo, 2017); and white-water kayakers (Bartram, 2001; Kane \& Zink, 2004). Serious 
leisure is divided into three main categories or forms of leisure: serious leisure, casual leisure, and project-based leisure. This immediately shows, their distinctive features, as well as any similarities between them and their interrelationships (Elkington \& Stebbins, 2014; Stebbins, 2007).

From the sociology sub-area of risk perspective, studies have emerged on voluntary risktaking in risky activities within nature sports. From the studies included in this scope, the compensation perspective (Le Breton, 2000; Lewis, 2004; Lyng, 2005; Pereira, 2009) and adaptation perspective (Beedie, 2007, Crosset \& Beal, 1997; Kusz, 2004; Palmer, 2004) have been highlighted. They belong to the two dominant schools of thought on sociological risk speech and interpret modernity in two completely different ways: in the compensation perspective, participation in risky activities is viewed as a break with the values of modernity; in the adaptation perspective, the same phenomenon is seen as following the values of (reflexive/late) modernity (Breivik, 2010; Langseth, 2011; Melo, 2017).

An important part of nature sports is related to the possibility it offers for mastery, significant experience and pleasure (Breivik, 2010). From a philosophical point of view, the components of the adventure experience especially associated with some nature sports were studied from the perspective of flow (Csikszentmihalyi, 1975; Mitchell, 1983). Similar to flow, some scholars studied voluntary risk-taking in relation to an understanding of the Kantian sublime: transcendency (Celsi, 1992; Stranger, 1999, 2011); spirituality (Watson, 2007); and the sublime (Illundáin-Aguruzza, 2007). Krein $(2008,2014,2015)$ also expressed the idea of interaction between nature and nature sports participants. Place is, in fact, a critical feature in the understanding the nature sports (tourism) experience and participation. Further, sport tourism and nature sports play a crucial role in delineating and confirming a sense of place and place identity (Gammon, 2015; Higham \& Hinch, 2009; Melo, 2017; Weed \& Bull, 2004).

Participation in certain so-called risk activities, such as nature sports, is often understood as the result of personal characteristics. Based on evolutionary psychology, the Sensation Seeking Scale (SSS) is a model that takes in to account the different predispositions for participation in such activities (Bouter, Knipschild, Feij, \& Volovics, 1988; Jack \& Ronan, 1998; Robinson, 1985; Trimpop, Kerr, \& Kirkaldy, 1998; Zuckerman, 1979). Other frameworks and theories understand the (nature sports) adventure experience: adventure experience (Vester, 1987); adventure experience paradigm (Martin \& Priest, 1986; Priest, 1990; Priest \& Gass, 1997); and adventure model (Ewert \& Hollenhorst, 1989, 1994). The relationship between experience and adventure involvement (McIntyre, 1992; Robinson, 1992), competence (Iso-Ahola \& Graefe, 1988; Swarbrooke, Beard, Leckie, \& Pomfret, 2003) and risk (Ewert \& Hollenhorst, 1994; Priest, 1992) has also been explored. Motivation and constraints are also useful in understanding nature sports (and sport tourism) behaviour, as presented in the following sections.

\section{Nature sports motivation}

Motivation is a broad subject in research about sport tourism and nature sports. Considering nature sports as a set of sports activities that are included in the active sport tourism segment, the motivation for participating in such activities must be viewed in terms of the intersection between tourism and sports motives and the ways in which these aspects influence each other. In this regard, Robinson and Gammon (2004) have presented two areas of focus: i) differentiating between those who travel primarily to participate in sports; and ii) those for whom sport is perceived as a secondary consideration.

Even though tourism and sport can be considered as separate activities involving a complex set of motivations, both sports participation and tourism share a number of common traits which may offer some insight into the uniqueness of the sports tourist (Weed \& Bull, 2004; Reeves, 2000) and nature sports participants. [General reviews about tourism motivation literature can be found in Ryan (2002), and Shaw and Williams (2002); a general review of sport motivation literature can be found in Roberts and Treasure (2012); while a general review on sport tourism motivations can be found in Weed and Bull (2004).] 
Nature sports participation: Understanding demand, practice profile, motivations and constraints.

During the 1960s, research about the motivations for nature sports and outdoor recreation was abundant. However, this research was generally limited to descriptions of participation in specific activities, such as canoeing or camping (Tarrant, Bright, Smith, \& Cordell, 1999). During the 1960s and 1970s, several researchers (e.g., Burch, 1969; Hendee, 1974) began to explore the theoretical nature of this motivation, although the most comprehensive studies have been carried out by Driver and colleagues (Driver \& Brown, 1978; Driver \& Knopf, 1976; Driver \& Tocher, 1970). Initially, these investigations had an approach centred on the outcome of the activity rather than the activity itself, which led Driver (1977) to consider motivation as the desired and expected psychological outcome resulting from participation in recreational activities. From this perspective, participants in nature sports have a specific behaviour that arises from a perception of the results associated with that behaviour. Thus, motivation is referred to as the desired consequences (Driver \& Knopf, 1976) and psychological outcomes (Driver \& Brown, 1978).

It was also suggested that the meaning of motivation is related to practitioners' expectations of either the conditions they would find or the experience of those activities (Schreyer \& Rogenbuck, 1978). The importance of studying motivations in nature sports is related to the potential for this to influence the satisfaction of individual needs, preferences, expectations and/or expected benefits (Tarrant et al., 1999).

Driver's (1977) work led to the development of psychometric scales that can be used to measure the dimensions of individual recreational experience. This became known as the Recreation Experience Preference (REP). The first empirical studies about motivation in nature recreational activities (Manfredo, Driver, \& Tarrant, 1996) were focused on: i) a descripttion of recreational experience preference in several activities; ii) the identification of different types of experiences enjoyed by different participants within the same activity; iii) the establishment of a relationship between the activity settings and preferences; iv) identifying the relationship between non-leisure conditions and recreational experience preferences; v) exploring the relationship between experience preferences and subject characteristics; and vi) the methodological development of REP scales.

The sum of personal motivations quantifies the preference for recreational experience. Therefore, REP scales can be used in a variety of ways, depending on how they are written and administered (Tarrant et al., 1999): a) if administered immediately before an activity, they test what motivates the participants to participate in that specific activity; b) if administered immediately after an activity, they test preferences or satisfaction; and c) if administered months after the activities or without a specific activity in mind, they test the preferences for recreation in general.

Chazaud (2004) presented a framework to study the motivation for participating in nature sports activities, divided into six dimensions: i) nature/environment - to be in contact with nature; to enjoy nature and the landscape; to protect the environment; ii) risk/adventure - to have new experiences/adventure sensations; to challenge your abilities; to put yourself to the test; iii) sociability - to fulfil free time; to interact with other people/social interaction; by the socializing context it provides; iv) hygienism medical advice/health reasons; for maintaining and/or enhancing the physical condition; relaxation/break from the everyday routine; v) competition - to be involved in a sports competition; and vi) tourism - to visit other sites/destinations; to learn about other traditions and other cultures; to visit and help protect the heritage.

Several studies have been conducted about motivation for participation in different nature sports activities, including, equestrian activities (Daniels \& Norman, 2005), geocaching (Falcão, Damásio, \& Melo, 2017), kite surfing and windsurfing (Hennigs \& Hallmann, 2014), paragliding (Chang \& Huang, 2012), rockclimbing (Woratschek, Hannich, \& Ritchie, 2007), sea kayaking (O'Connell, 2010), surfing (Reynolds \& Hritz, 2012), white-water rafting (Flucker \& Turner, 2000), and other outdoor activities (Wang, Ang, Teo-Koh, \& Kahlid, 2004; Festeu, 2002; Sugerman, 2001). In the 50 studies he reviewed, Buckley (2012) 
identified at least 14 different categories of motivation for nature sports and adventure activities, which he divided into three dimensions: i) internal, performance of activity (thrill, fear, control, skills, achievement, fitness, and risk); ii) internal/external, place in nature (nature, art, spirit); and iii) external, social position (friends, image, escape, and competition).

\section{Nature sports constraints}

Participation in sport tourism and nature sports is also characterized by constraints (Hinch, Jackson, Hudson, \& Walker, 2005). Alone, motivation does not explain participation in these activities because certain factors seem to deny the individual motivations and the ability to participate in these activities. Jackson (1988) defined constraints as factors that can inhibit participation in leisure activities or limit satisfaction in participation. Leisure constraints are also defined as barriers, obstacles or inhibitor factors, perceived or real, that influence the participation of an individual, the frequency, intensity, duration, quality, choice, or freedom of choice in a leisure activity (Goodale \& Witt, 1998).

Investigations into constraints on participation in nature recreational activities arose in the 1960s with the United States Outdoor Recreation Resources Review Commission (Goodale \& Witt, 1998; Jackson \& Scott, 1999). However, the systematic investigation into leisure constraints, as a leisure research subarea, emerged with some of the key publications in the 1980s (Jackson, 2005b). The work of Crawford and Godbey (1987) presented one of the most significant theories in this field. These researchers presented a model that categorizes constraints into three types: i) intrapersonal factors - defined as individual psychological qualities affecting the development of the leisure preferences (e.g., fear of getting injured in rock-climbing); ii) interpersonal factors - defined as the social factors affecting the development of the leisure preferences (e.g., lack of company to climb); and iii) structural factors - defined as the factors that intervene in the development of and participation in leisure preferences (e.g., lack of money to buy the equipment needed to climb). Extending this line of thought, Crawford,
Jackson and Godbey (1991) presented a hierarchical model of leisure constraints importance, ranging from the nearest (intrapersonal) to the farthest (structural). This model suggests that intrapersonal and interpersonal factors influence leisure preferences and that the structural factors intervene in preferences and participation.

Jackson, Crawford and Godbey (1993) developed an alternative view of the constraints participation in leisure activities, which was designated "Constraint Negotiation". The central preposition of this theory is that participation in leisure is not dependent on the absence of constraints but on their negotiation (Jackson et al., 1993). Later, Jackson and Scott (1999) developed a model of leisure constraints, based on the interplay between motivation, constraints and preferences. Recently, advances in leisure constraints theory and research methods placed negotiation within a broad context of leisure behaviour, and explored the relationship between constraints and other concepts: the relationship between motivation, perceived constraints and participation (Hubbard \& Mannell, 2001); constraints, preference and motivation (Hubbard \& Mannell, 2001; LoucksAtkinson \& Mannell, 2007; Mannell \& LoucksAtkinson, 2005); and constraints and selfefficacy (Henderson, Bedini, Hecht, \& Schuler, 1995; Hubbard \& Mannell, 2001). A construct of negotiation effectiveness was also developed by Loucks-Atkinson and Mannell (2007).

White (2008) extended the previous investigations of Mannell and colleagues (Hubbard \& Mannell, 2001; Loucks-Atkinson \& Mannell, 2007), conducting an empirical test of a conceptual model of negotiating constraints in the context of recreation in nature. The model proposes that motivation is directly and positively related to participation in nature recreational activities, and that the positive influence of motivation is neutralized by the negative influence of constraints. This model also suggests that these relationships tend to be influenced by efforts to negotiate: greater motivation for participation in nature recreational activities is likely to encourage the use of negotiation strategies and resources to 
overcome the constraints. Experience in constraints, however, also has an indirect positive impact on participation, triggering or activating negotiation efforts: the effectiveness in negotiating encourages motivation, decreases the perception of constraints, and encourages the use of negotiation efforts, thus presenting an indirect positive influence on participation.

Based on the idea that the constraints to recreation and leisure are not distributed equally in society, some authors (Jackson \& Henderson, 1995; Johnson, Bowker, \& Cordell, 2001) demonstrate that the socio-demographic characteristics (macro-level factors) play an important role in prevalence and degree of constraints, and may be more significant for those who fall into non-dominant groups (Henderson \& Hickerson, 2007). In line with this, some authors associate constraints with recreation and leisure, to describe the various systems of inequality, considering how multiple identity factors such as gender, race, social class and residence, interact with and influence the preferences and leisure constraints (Johnson et al., 2001; Virden \& Walker, 1999).

From this perspective, multiple hierarchical stratification perspective emerged, based on the idea that each person has a position or status in society (Shores, Scott, \& Floyd, 2007). This was developed as a distinct theoretical perspective, although it is conceptually linked to other sociological theories such as status characteristics and structural social theories (Shores, Scott, \& Floyd, 2007). According to Markides, Liang and Jackson (1990), this perspective was developed to understand how multiple status disadvantages compromise access to a range of public services, including recreational resources. According to Shores, Scott and Floyd (2007), the theory of multiple hierarchy stratification features a model in which older women who are poor and members of a minority group are associated with a greater number of service access constraints, and are positioned at the lower end of the stratification hierarchy. At the opposite pole, however, young white and wealthy men (who have the smallest constraints on access to leisure) are positioned at the higher end of the hierarchy.
Walker and Virden (2005) presented a model that shows micro level (personality traits, human needs, attitudes and beliefs, etc.) and macro level (race, gender, cultural forces, socioeconomic forces, etc.) factors, when combined with motivation, have a cumulative effect on leisure preferences. Walker and Virden (2005) presented a classification of specific constraints to the study of recreation in nature, proposing a constraints classification divided into four structural constraints: i) natural environment structural constraints; ii) social environment structural constraints; iii) territorial structural constraints; and iv) institutional structural constraints.

Investigations into motivations produced results demonstrating that the constraints for outdoor recreation practices varied significantly depending on participants' characteristics such as ethnicity, social class, location and activity (Cordell et al., 1999). For example, poor people in urban centres consider lack of money and transportation to be their main constraints, while people with disabilities consider individual health and inadequate accessibility to be major constraints to practicing nature recreational activities (Cordell et al., 1999). Gender is also a determining factor for these activities (Henderson \& Dialeschkia, 1991; Henderson \& Hickerson, 2007; Johnson et al., 2001). Rojek (1985) states that women experience a unique set of barriers that are not as evident in men, and which relate both to the structure of the sexual role imposed on women and to concerns they present as perceived sex objects in a male-dominated patriarchal society.

Another trend based on recent research/data about constraints in the practice of nature recreational activities is the prevalence of certain barriers that are common to all populations and activities (Scott \& Kim, 1998; Walker \& Virden, 2005): i) lack of time; ii) lack of money; iii) personal health; and iv) lack of company. Along the same lines, Walker and Virden (2005) reported that the constraints to these practices are similar to those in other leisure contexts (and life) but that some constraints, such as lack of time, can have a greater impact in the context of nature sports. This is because of the commitments required for the trips that are sometimes necessary in 
order to reach suitably remote natural areas outside of the usual residential zones.

\section{Methodology}

Selected nature sports activities

Based on analysis of several studies (Carvalhinho, 2006; DECO, 2008) and the Portuguese law (Ministério das Cidades Ordenamento do Território e Ambiente, 2003), 47 distinct activities that could be included in the scope of nature sports were identified, and were considered to be part of this study. However, some were excluded, according to the following criteria: i) those not practiced in direct contact with nature (e.g. bungee jumping); ii) those at odds with the values of the nature conservation, such as the motorized sports (e.g. motocross); iii) those which are complementary to core activities (e.g. camping); iv) those developed under the scope of others (e.g. observation of fauna and flora); v) those which are variants or specialties of core activities (e.g. cross country or downhill that are specialties within MTB); vi) those not widely practiced in the Portuguese territory (e.g. hidrospeed). This meant that 23 activities were identified as eligible to included in this study: 1) equestrian activities; 2) bodyboarding; 3) MTB; 4) kayaking; 5) canyoning; 6) rockclimbing; 7) caving; 8) skiing; 9) kitesurfing; 10) scuba diving; 11) mountaineering; 12) orienteering; 13) trekking; 14) rafting; 15) rowing; 16) skimming; 17) snowboarding; 18) surfing; 19) archery and crossbow; 20) sailing; 21) free flight; 22) windsurfing; and 23) multiactivities (e.g. adventure running; adventure challenge, etc.).

Questionnaire, sampling, data collecting and processing

This study used an online survey questionnaire built in the LimeSurvey platform. The instrument was composed of 40 questions, including socio-demographic characteristics, demand profile, practice behaviour, motivation and constraints. The questionnaire comprised questions with mostly closed responses, using nominal, ordinal and continuous scales. In the latter case, a five-point scale was used. The questionnaire was validated via pre-testing application and expert examination.
The questionnaire was applied to nature sports participants living on the Portugal mainland, aged at least 18 years old, and who had practiced at least one of the 23 selected nature sports activities during the year 2010. Whereas it was not possible to determine the exact total number of nature sports participants in Portugal, the questionnaire was applied to a convenience sample of balanced criteria which took into account the following criteria: a) the activity that was practiced (from the 23 that were selected); b) the type of participant (formal, non-formal or informal); c) age, sex and region (there are 18 districts on mainland Portugal). The questionnaire was disseminated in accordance to these criteria, as an electronic link. The most common forms of dissemination were: mailing lists (groups of friends of practitioners, sports clubs, associations, practitioners' clubs and touristic companies); Facebook, Blogspot and websites of organizations and participants that promote these activities. A total of 1126 questionnaires were completed and therefore included in our analysis.

Data gathered through the questionnaires was subjected to statistical treatment using Statistical Package for Social Sciences software (SPSS v.20, SPSS Inc., Chicago, IL). Results were presented through descriptive statistics using means and standard deviations for continuous variables, and percentages for nominal and ordinal variables (Marôco, 2010). Measures of association were based on Chisquare, estimating the degree of association between variables through the Contingency Coefficient and Cramer's V, as described in Marôco (2010). Standardized Adjusted Residuals (SAR) were used to identify cells in the contingency table with significantly different behaviours from expected behaviours between variables. To explain the relationship between the categories of the variables, the residuals of less than -1.96 or greater than 1.96 were used (Pestana \& Gageiro, 2003, p. 140).

\section{Results and discussion}

Socio-demographic characteristics of nature sports participants in Portugal

The distribution of individuals of our sample indicates that $66.4 \%$ of respondents were male and $33.6 \%$ were female (see Table 1). The average age of respondents is 34 years ( \pm 
14.4). The results distributed by age groups indicate a predominance of respondents between 18 and 43 years $(81.4 \%)$. The older the age group, the fewer the participants, indicating that participation in nature sports decreases as participants age. Half $(51.3 \%)$ of the respondents were single and a large proportion (41.8\%) were married/living with partner. By crossing the marital status and sex variables, it can be observed that most $(64.0 \%)$ women were single, while the men were just as likely to be between married/living with partner $(49.1 \%)$ as single (44.9\%). Most (61.3\%) respondents stated that they had achieved academic qualifications at higher education level: $41.0 \%$ of respondents had completed a bachelor's degree; $16.8 \%$ had a master's degree; and $3.5 \%$ a $\mathrm{PhD}$. When comparing these data with the Portuguese population data
(Instituto Nacional de Estatística, 2011), it can be observed that nature sports participants have an education level very above the average of the Portuguese population: $73 \%$ of whom have progressed no further that the third-cycle level ( $9^{\text {th }}$ grade), while almost all $(91.3 \%)$ of nature sports respondents have education levels equal to or higher than secondary education (12 ${ }^{\text {th }}$ grade). The data also shows that the sample is predominantly composed of employed individuals $(67.4 \%)$, who are working for others $(57.0 \%)$, and who are in highly qualified jobs (43.4\%). Regarding economic capital, the sample is composed of individuals with a high monthly net income, compared to the average of employed Portuguese citizens (809 Euros) (Instituto Nacional de Estatística, 2013): $43 \%$ of the participants are included in a high income

Table 1. Socio-demographic characteristics of nature sports participants in Portugal.

\begin{tabular}{|c|c|c|}
\hline \multirow{2}{*}{ Socio-demographic variables } & \multicolumn{2}{|c|}{ Total } \\
\hline & $\mathbf{n}$ & $\%$ \\
\hline \multicolumn{3}{|l|}{ Gender (\%) } \\
\hline Female & 378 & 33.6 \\
\hline Male & 748 & 66.4 \\
\hline Age (mean in years and std. dev.) & $34( \pm 14.4)$ & \\
\hline \multicolumn{3}{|l|}{ Age groups $(\%)$} \\
\hline $18-30$ & 485 & 43.1 \\
\hline $31-43$ & 431 & 38.3 \\
\hline $44-56$ & 159 & 14.1 \\
\hline 57 and older & 51 & 4.6 \\
\hline \multicolumn{3}{|l|}{ Marital status } \\
\hline Single & 578 & 51.3 \\
\hline Married/ living with partner & 471 & 41.8 \\
\hline Divorced/separated & 68 & 6.0 \\
\hline Widow & 9 & 0.8 \\
\hline \multicolumn{3}{|l|}{ Education level (\%) } \\
\hline Doctorate degree & 39 & 3.5 \\
\hline Master degree & 189 & 16.8 \\
\hline Graduate degree & 462 & 41.0 \\
\hline Secondary education $\left(12^{\text {th }}\right.$ grade $)$ & 378 & 33.6 \\
\hline Basic education ( $9^{\text {th }}$ grade) & 58 & 5.2 \\
\hline \multicolumn{3}{|l|}{ Main professional group (\%) } \\
\hline Public/private senior manager & 223 & 19.8 \\
\hline Scientific/intellectual profession & 266 & 23.6 \\
\hline Intermediate level technician & 294 & 26.1 \\
\hline Other & 343 & 30.5 \\
\hline \multicolumn{3}{|l|}{ Monthly income (\%) } \\
\hline Without income & 206 & 18.3 \\
\hline$\leq 500 €$ & 68 & 6.0 \\
\hline $501-750 €$ & 121 & 10.8 \\
\hline $751-1000 €$ & 184 & 16.3 \\
\hline $1001-2000$ & 382 & 33.9 \\
\hline $2001-3000 €$ & 66 & 5.9 \\
\hline$\geq 3001$ & 39 & 3.5 \\
\hline Don't know/Don't answer & 60 & 5.3 \\
\hline
\end{tabular}


echelon; $16 \%$ are included in the average echelon; and $16 \%$ are students without income. Those participating in the study are nature sports participants living mostly in the coastal regions of Portugal.

\section{Demand for nature sports}

The results of this study show that MTB is the activity that is practiced by most individuals, at least once in their lives $169.9 \%$ of those interviewed claimed to have practiced this activity), followed by kayaking $(63.8 \%)$ and hiking $(56.0 \%)$, as shown in Table 2 . The nature sports activity that most respondents like to practice is MTB (16.9\%), followed by trekking (11.4\%), kayaking $(8 \%)$ and mountaineering (8\%). Regarding the results from the most frequently practiced activities, MTB $(22.7 \%)$ is the activity most practiced by more individuals, followed by trekking (17.6\%) and kayaking $(7.8 \%)$. In analyzing the three activities that respondents wanted to practice more often, it was found that MTB had the highest total percentage $(36.3 \%)$ of the sum of the three responses (first, second and third choice), followed by mountaineering $(27.9 \%)$ and kayaking $(24.3 \%)$.

Results show a strong positive correlation ( $p$ value $<0.050$ and Cramer's $V=0.690$ ) between the activities undertaken more frequently and the activities that the respondents most like to practice (first option), highlighting that respondents in general have a satisfied demand in relation to nature sports activities. Analysis between nature sports activities practiced more frequently and the activity that respondents wish to carry out more frequently (first option) points to a strong positive correlation ( $p$-value $<0.050$ and Cramer's $\mathrm{V}=$ $0.516)$. In general, SAR analysis indicates that the nature sports activity which is referred to as the most commonly practiced matches the activity that respondents wish to carry out more frequently, verifying significantly positive correlations between them. As seen in the previous analysis, these data demonstrate that in addition to a satisfied demand, individuals would like to carry out this activity more often, which may presuppose the existence of constraints that prevent them from practicing this activity more often.
To determine the potential demand for nature sports, the differences (obtained by subtracting the respective percentages) between the three activities that individuals would like to practice more often and those activities most frequently practiced was used. Results show that mountaineering is the activity with a higher potential demand $(21.5 \%)$, as $27.9 \%$ would practice it more often, while it is the more frequently practiced activity for only $6.4 \%$ this (subtraction between $27.9 \%$ and $6.4 \%$ ); followed by diving and kayaking with a potential demand of $19.1 \%$ and $16.5 \%$ respectively.

Statistical tests also indicate a moderate positive correlation ( $p$-value $<0.050$ and Cramer's $V=0.391$ ) between the activities practiced more frequently, in terms of sex. It is noted that trekking $(33.1 \%)$ is the activity practiced with higher frequency by a greater number of women, followed by MTB (11.8\%) and kayaking (9.2\%). In contrast, MTB (31.1\%), trekking $(11.6 \%)$ and kayaking $(8 \%)$ are the activities practiced more frequently by the largest number of surveyed males. Moreover, SAR analysis highlighted that trekking $(\mathrm{SAR}=8.5)$, equestrian activities $(\mathrm{SAR}=3.0)$, skiing $(S A R=3.0)$, skimboard $(S A R=2.6)$ and multi-activities $(S A R=2.0)$ are the nature sports practices that women present a greater willingness to practice, while bodyboarding $(\mathrm{SAR}=3.0), \quad \mathrm{MTB} \quad(\mathrm{SAR}=6.6)$, free flight $(\mathrm{SAR}=2.8)$ and windsurfing $(\mathrm{SAR}=2.3)$ are the activities that men have a higher predisposition to practice. Results do not show statistically significant differences in the remaining activities.

In the analysis between the activities practiced more frequently by age, results showed a weak positive correlation ( $p$-value $<0.050$ and Cramer's $V=0.234$ ). By analyzing the trend of the relative participation (expressed as a percentage of the number of respondents in each age group) in the activities practiced with higher frequency, which received more than 35 responses (bodyboarding, MTB, kayaking, rock climbing, mountaineering, diving, orienteering, trekking and surfing), relevant data were verified according to advancing age (see Figure 1). 
Nature sports participation: Understanding demand, practice profile, motivations and constraints.

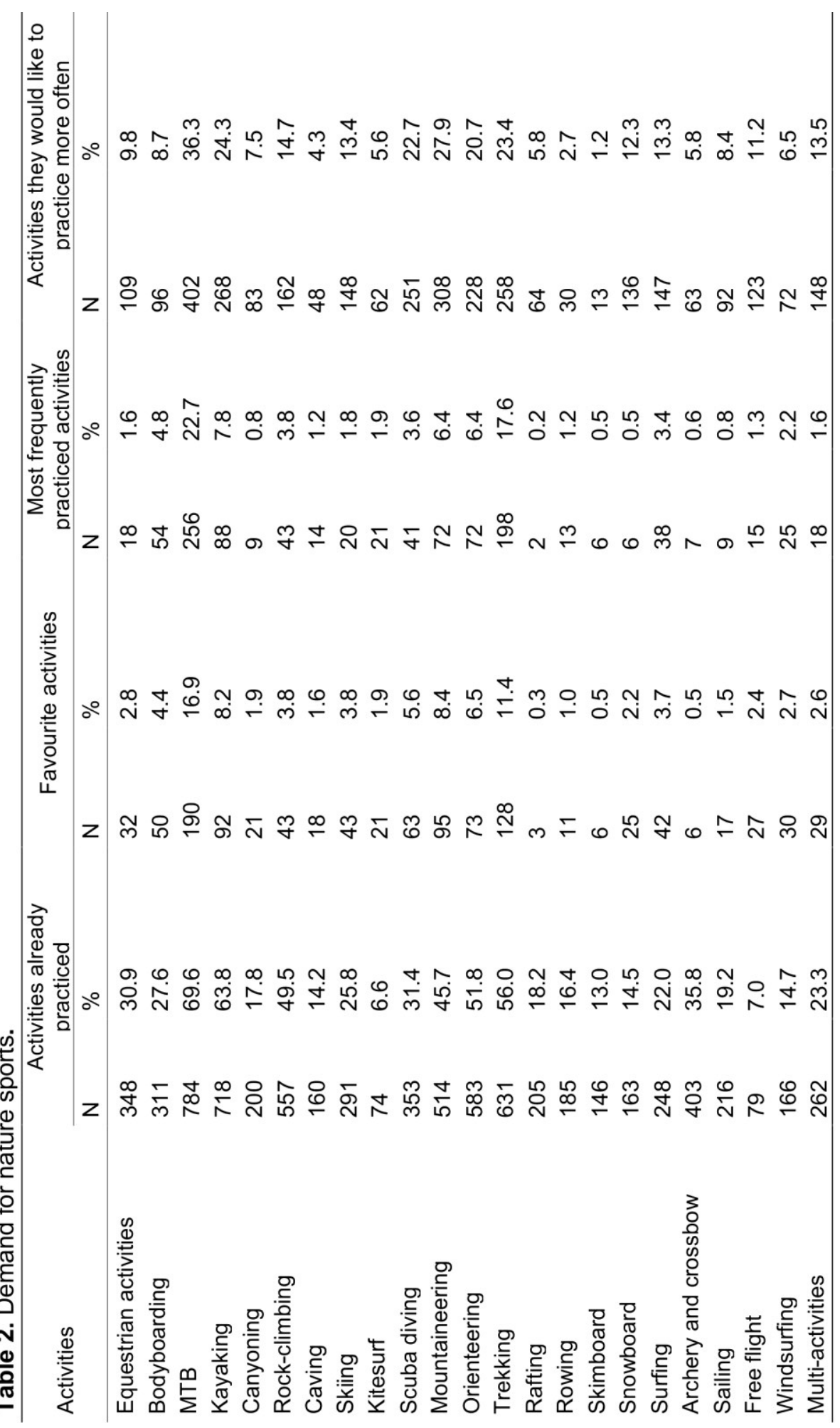




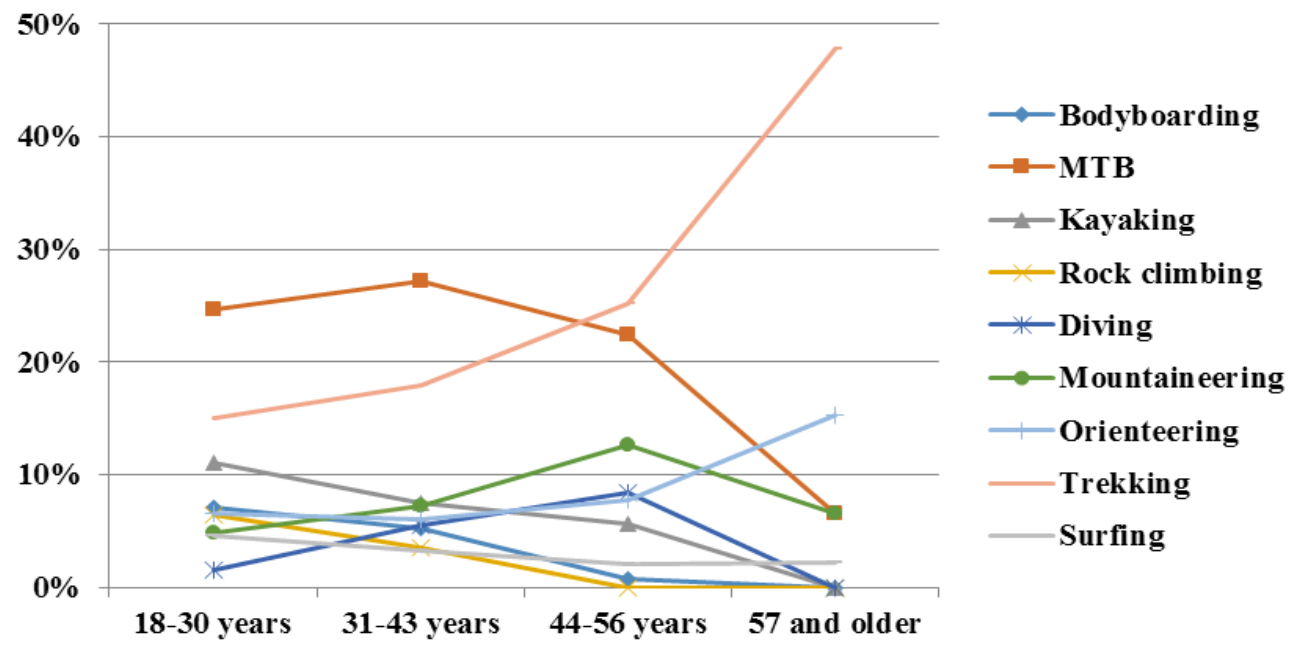

Figure 1. Participation tendency in nature sports by groups of age.

MTB (24.6\%), trekking (14.9\%) and kayaking $(11.0 \%)$ are the activities undertaken more often by more individuals in the lower age group (18-30 years). MTB (27.2\%), trekking $(18 \%)$ and kayaking $(7.5 \%)$ remain the activities more often practiced by a higher number of individuals in the second age group (between 31-43 years). Having said this, the first two activities show a relative growth trend, while kayaking has a tendency of relative decrease compared to the first group. Trekking $(25.2 \%)$ appears to be the most frequently practiced activity by more individuals in the group between 44-56 years age group, followed by MTB (22.4\%) and mountaineering $(12.6 \%)$. Finally, in the more advanced age group (over 56 years), trekking (47.8\%) remains as the activity that is practiced more often (with an upward trend over the previous relative group), followed by orienteering $(15.2 \%)$, MTB $(6.5 \%)$ and mountaineering $(6.5 \%)$.

Orienteering oscillates between the first three age groups, and has a relative growth in the last group, where a positive participation trend $(S A R=2.3)$ to carry out this activity is shown. Trekking has a relative increase with advancing age, with a negative participation trend (SAR=2.9) in the lower age group and a positive participation trend $(S A R=1.9)$ in both of the older age groups to carry out this activity, particularly in the aged over 56 years group
(SAR=5.6). In contrast, kayaking presents a relative decrease as age advances, denoting a greater likelihood $(S A R=2.6)$ of practice in the aged 18-31 years group, and it being less likely (SAR=-2.1) in the advanced age group. Bodyboarding follows the same pattern as kayaking. The number of participants in surfing activities also decreases with age. Rockclimbing results show only responses in the first two age groups, particularly in the first, where there is a positive trend $(\mathrm{SAR}=3.3)$ for the practice of this activity. MTB achieves the highest relative percentage of participants is in the aged 31-43 years group, and it then decreases with advancing age, reaching the last group a negative trend (SAR=-2.9) for its development. Mountaineering presents a negative trend (SAR=-2.9) in the aged 18-30 years group and has a relative growth in the aged 44-56 years group, which shows a positive participation trend $(S A R=2.9)$ for this practice, subsequently decreasing to the last group (aged over 56 years). Scuba diving follows the same pattern as mountaineering in the first three age groups, despite it not having any participants in the older age group.

\section{Nature sports practice profile}

This section characterizes nature sports practice behaviour (see Table 3). Results show that respondents are generally recent nature sports participants $(55.0 \%$ with less than 10 years of experience) with a perception of 
intermediate level of technical proficiency (53.4\%). Statistical tests indicate a lower positive correlation ( $p$-value $<0.050$ and Cramer's $V=0.281$ ) between the level of technical proficiency and the number of years practicing nature sports. Generally, more years practicing (15 years or more) is correlated with a perception of a more advanced level of technical proficiency $(S A R=10.8)$, while fewer years practicing (4 years or fewer) is correlated with a perception of a beginner's level of technical proficiency (SAR=8.6), and a correlation between individuals with 5-9 years of experience and a perception of an intermediate level of technical proficiency (SAR=2.9).

Results show that men present a greater number of years of practice than women, as well as a perception of a higher level of technical proficiency. There is also a direct relationship between the age of the participants and the average age at which they began practicing nature sports, verifying the progressive increase in the average age at which participants began practicing nature sports with the age of the participants. These data suggest that the practice of nature sports is a recent phenomenon of sport tourism in Portugal. It also shows great potential for growth, verifying an early beginning of this practice, with the largest number of participants located in the younger age group.

Most respondents $(53.6 \%)$ were influenced by their social group (friends, co-workers, neighbours or family) to start practicing nature sports, while $33.6 \%$ initiated it autonomously. Differences by gender highlight a greater tendency for men to start the practice in an autonomous way $(\mathrm{SAR}=2.3)$ and because of media (SAR=2.1), while women are more likely than men to have been influenced by school $(\mathrm{SAR}=4.2)$.

Influences in beginning the practice also vary according to which nature sport activity is practiced and by the age at which practice begins. A considerable number of scuba divers $(62.5 \%)$ started this practice autonomously, while the practice of kayaking was especially encouraged by the sociability group $(66.7 \%)$. On the other hand, schools began to make an important contribution to beginning nature sports practice as the lowest age group (18-30 years) presented a greater tendency to have been influenced by school (SAR $=6.7$ ) while this was a lower trend in the other groups. This tendency is very evident in orienteering (SAR = 3.7) and rock-climbing (SAR = 5.9). However, school influence in starting MTB is significantly lower (SAR=-3.4) than in the other activities. These data suggest that the inclusion of some nature sports activities in the curriculum of physical education programs (1st, 2nd and 3rd cycles and at secondary level), as in the case of orienteering and rock-climbing, has been crucial to encouraging the practice of these sports activities. These data also suggest that an inclusive policy that offers a wider range of other nature sports activities may have an influence on the elimination of asymmetries evident in participation (sex, age, and social, cultural and economic capital), and a positive influence in increasing the number of nature sports participants and the index of sport (tourism) participation in general, in Portugal.

Most respondents (47.3\%) stated that they started developing the activity they practice more often in an informally way, with their social group (friends, co-workers, neighbours or family members), as a form of recreation. Results show that there is a moderate positive correlation ( $p$-value $<0.050$ and Cramer's $\mathrm{V}=$ 0.466 ) between the beginning social and organizational context and the current one, which shows only a slight exchange between the initial context and the current. Generally, what is denoted is an increasing participation in the associative context (sports clubs, associations and practitioners clubs) and in the informal context of the social group, and a reduction in the practice within the business and autonomous contexts.

Analysis of the results from the nature sports activities carried out most frequently, in terms of socio-organizational scope of practice, shows statistically significant differences presenting a moderate association ( $p$-value $<0.050$ and Cramer's $V=0.349$ ). Analysis of SAR of the nine activities developed more often by the largest number of respondents (up to 35 replies) by socio-organizational scope of practice shows a following tendency: 
$\checkmark$ Sport clubs - Kayaking $(S A R=5.1)$, orienteering (SAR = 14.5), rowing $(S A R=6.8)$, archery and crossbow $(\mathrm{SAR}=3.2)$ and free flight $(S A R=5.0)$ are the nature sports activities that have a higher predisposition to be developed in this context, while; bodyboarding $(\mathrm{SAR}=-2.3)$, MTB (SAR=-4.1), scuba diving $(\mathrm{SAR}=-2.2)$, trekking $(\mathrm{SAR}=-4.4)$ and windsurfing $(S A R=-2.1)$ are the activities that have the lowest development trend in this context;

$\checkmark$ Practitioners' clubs - Scuba diving $(\mathrm{SAR}=4.4)$ has a positive potential, while; MTB has a negative potential $(S A R=-2.8)$ to be developed in this context;

$\checkmark$ Sports associations - Caving (SAR=4.8) and trekking $(S A R=4.8)$ are the activities that have the greatest development potential in this context, while; MTB (SAR=-2.8) and surfing (SAR=-2.2) are those with less potential;

$\checkmark$ Sport tourism companies - Kayaking $(\mathrm{SAR}=5.6)$, scuba diving $(\mathrm{SAR}=5.6)$, and surfing $(S A R=2.0)$ are the activities that have the greatest development potential in this context, while; MTB (SAR -2.7), and trekking $(S A R=-2.2)$ are the activities that show the lowest potential;

$\checkmark$ Informal group - MTB (SAR=6.4), skiing (SAR=2.3), mountaineering (SAR=2.0), snowboarding $(\mathrm{SAR}=2.3)$ and surfing $(S A R=2.0)$ are the activities with the greatest potential, while; equestrian activities (SAR=2.9), kayaking ( $S A R=-4.0)$, caving ( $S A R=-2.7)$, orienteering ( $S A R=-7.5)$, rowing ( $S A R=-3.1)$, archery and crossbow (SAR=-2.8), and free flight $(S A R=-4.1)$ are the activities that have lower development potential in this context;

$\checkmark$ Individual - Equestrian activities (SAR=3.3) are evident as an individual practice.

In terms of frequency, the majority (43.9\%) of responding practitioners have a regularly practice (at least once a week), while $25 \%$ practice sporadically (without regular frequency). However, there are statistically significant differences ( $p$-value <0.050) in the frequency of practice between the various activities. Surfing (68.4\%), bodyboarding $(66.7 \%)$ and MTB $(62.1 \%)$ are activities that show the highest practice frequency, usually more than once a week. On the other hand, mountaineering $(58.3 \%)$, trekking $(56.6 \%)$ and scuba diving $(48.8 \%)$ are the activities that are practiced with less regularity, mostly carried out during holidays and long weekends, or without regular frequency.

There are also significant statistical differences ( $p$-value $<0.050)$ between the various nature sports activities and the preferred time of the year for their practice. Analysis of the nine activities that have obtained more answers shows that kayaking $(S A R=6.0)$ and scuba diving $(S A R=3.9)$ are practiced mainly during the summer, while the remaining are mostly practiced indistinguishably throughout the year, especially orienteering $(S A R=3.3)$ and MTB $(S A R=2.0)$. On the other hand, bodyboarding has a greater tendency than others to take place in autumn (SAR=2.4) and winter (SAR=2.9), and mountaineering also has a greater tendency to only take place in winter (SAR=2.3).

Most participants (56.4\%) are active during the weekend, while $33.9 \%$ practice indistinguishably across the week. However, analysis shows significant statistical differences ( $p$-value $<0.050)$ between the different nature sports activities: bodyboarding $(\mathrm{SAR}=4.3)$ and surfing $(S A R=3.5)$ present a greater tendency to be practiced indistinguishably across the week, while scuba diving $(S A R=2.8)$, mountaineering $(\mathrm{SAR}=3.3)$, orienteering $(\mathrm{SAR}=3)$, and trekking $(\mathrm{SAR}=3.5)$ are carried almost exclusively over the weekend.

In general (43.3\%), participants do not have a preferred time of day for practicing nature sports, while $34.3 \%$ prefer to practice their activities during the morning. However, a statistically significant difference is denoted ( $p$ value $<0.050$ ) between the practice of different nature sports activities. MTB $(S A R=4.1)$ and scuba diving $(S A R=2.3)$ are performed preferably during the morning, while rock climbing presents a negative predisposition to be practiced during the morning ( $S A R=2.5$ ). Scuba diving is never practiced during the evening or at night.

Most $(46.5 \%)$ participants stated that the duration of practice is usually between two to four hours, followed by less than two hours (reported by $23.4 \%$ ). However, significant statistical differences are denoted ( $p$-value 
Nature sports participation: Understanding demand, practice profile, motivations and constraints.

$<0.050$ ) between different nature sports activities. Orienteering is the activity that typically has a shorter duration, at less than 2 hours $(58.3 \%)$. On the other hand, mountaineering is the nature sports activity that normally has a greater duration, since, for $29.2 \%$ of its practitioners, this activity takes place for more than one day.

Most of the respondents $(74.0 \%)$ stated that they do not have a fixed place to practice, while only $26 \%$ said that they always practice at the same place, nevertheless highlighting significant statistical differences ( $p$-value $<0.050$ ) between the different nature sports activities. It is noted that kayaking $(58 \%)$ is preferably always held in the same place.

A portion of respondents $(35.7 \%)$ stated that they prefer to practice nature sports activities in their county of residence, while $19.0 \%$ generally practiced outside of their county of residence (although in the same district), and $19.7 \%$ practice outside their district of residence. The main difference ( $p$-value $<0.050$ ) is noted in MTB, which has a greater tendency to be held in the county of residence $(\mathrm{SAR}=6.0)$, while scuba divers $(\mathrm{SAR}=2.2)$ and mountaineers $(S A R=6.0)$ show a greater tendency than others to practice their activities outside of their country. Mountaineering has also a greater tendency to be practiced outside of the district of the participants' residence $(\mathrm{SAR}=3.0)$.

There are differences in the regularity and frequency with which nature sports activities are practiced, as well as in the time of week and year, the duration and the geographical location of practice areas. Several factors explain this. First, it appears that activities that require very particular conditions (geographical, weather, etc.) and that require specialized spaces, or which are located in specific areas and are less abundant in Portuguese territory, have a lower level of regularity and frequency than to the others. The case of mountaineering is a good example as it is an activity that is carried out in mountain areas. In most cases, this requires more significant travel (out of the district or the country, according to practitioners) in order to practice. It is also why it is practiced for one day or more, and preferably during the weekend. Participants look for different spaces in which to develop mountaineering, in order to constantly expand their experience of this eminently contemplative activity.

Scuba diving is another highly specific activity which includes significant environmental conditions in its practice. It is an activity that requires an appropriate aquatic-maritime space in order to develop, usually with good, stable water conditions (for this reason, it is an activity preferably practiced in summer), and visibility (for this reason, it is not usually practiced in the late afternoon or evening). As these specific conditions exist only in certain places, there is a need to travel outside of the district or country of residence in search of the best places, which explains a less regular frequency than in the other nature sports activities.

Rock-climbing is also an activity that, from the point of view of the space used, has some particularities. Rock-climbing as a sport usually takes place on cliffs with rocky walls which have varying levels of difficulty. It is also one of the nature sports activities that require great knowledge and technical expertise, in terms of safety procedures. This activity is usually practiced by groups of at least two (one individual climbing and another as security), to ensure security in practice. Data shows that this activity is mostly practiced by an informal group (friends, co-workers, neighbours, family members) as recreation for between one and three days a week, or sporadically without regular frequency, throughout the year, but mostly preferred in the summer. It is preferably practiced during the weekend, and indistinguishably throughout the day from two hours to a whole day. Usually, rock-climbing participants seek different areas of practice so they can climb different routes, with different difficulty levels, as evidenced by the results. Portugal has excellent conditions to carry out this activity in almost all territory, as the rock climbers do not need to leave the county or district of residence to carry out this activity.

Portugal also has excellent conditions for the practice of maritime sport activities involving waves, such as bodyboarding and surfing, as has been evidenced by the growing number of 
events that have taken place, particularly the world Surf League Tour that was been held in Peniche, and the creation of the world surfing reserve in Ericeira, which was the first in Europe. Areas in which to practice these activities are located in the coastal areas of the country, which is also where the biggest concentration of the Portuguese population resides. In this regard, these are practices of proximity, as shown by the results of this work (preferably developed in the county or district of residence), and in this case developed with a high frequency (usually more than once a week). Sea conditions (waves) required for the practice of these activities lead surfers to move around, looking for the best surfing spots which, in turn, leads them not to practice in a fixed location. These activities are practiced very frequently (interchangeably) throughout the week, and indistinguishably throughout the day because wave conditions will vary with tides. One reason for these results may be because these activities are mainly practiced by the younger age group (18-30 years),composed mostly of student, who are unmarried and without children, which implies greater freedom and a greater possibility of managing their own time.

This latest data shows that the profile of practitioners can also be a determining factor in the practice profile. One of the best examples is given by the practice of MTB. This activity does not require a space with such specific conditions as the previous activities and is therefore carried in the county or district of residence, without a fixed place, throughout the year, with a high frequency. However, this activity is mainly practiced by individuals who have an active working situation. Most of them are married or living with a partner and children which, in these circumstances, makes time a greater constraint, and which may explain that this activity is preferably practiced on weekend mornings.

Practice behaviour also seems to be influenced by social and organizational contexts. An example of this influence is provided by kayaking. This activity is practiced both in a sports club and in an informal group (friends, co-workers, neighbours, family members) as recreation, but, presents a greater tendency than other nature sports practices to be practiced as part of sport tourism companies $(S A R=5.6)$. Those who practice in sports clubs do it on a regular basis and more frequently, mostly more than once a week, throughout the week, and at all times of the year, while those practicing in an informal context have a greater tendency to practice sporadically, without regular frequency, at the weekend, and especially during the summer.

Orienteering is also an activity that presents a different profile depending on the socioorganizational context where it is practiced. This activity is mainly practiced in a sports club at least once a month, or several times per week, throughout the year. It is preferably carried out during the weekend. It can be seen that, during the week, a workout takes place that has a greater physical component than technical aspects of the practice (map reading, etc.), and that the more complete activity is reserved for the competitions days, which tend to take place at weekends, usually for two hours at the most. Due to its highly competitive scope, this activity is carried out in various parts of the country, with no fixed location for its practice.

On the other hand, trekking is an informal practice, mostly carried out within a social group (friends, co-workers, neighbours, family members) in a leisure context. It is an activity practiced without irregular frequency, generally throughout the year. It belongs to the group of nature sports activities designated as contemplatives, where trekkers seek different spaces for their development and require mobility in the county, the district or outside of the district of residence. It is an activity that generally takes place at the weekend, at any time of day (or preferably during the morning), for between two and six hours.

\section{Motivations for the practice of nature sports}

The motivations results (Table 3 ) show that nature (to be in contact with nature; to enjoy nature and the landscape; to protect the environment) is the most important reason that respondents highlighted for the practice of nature sports, with an average of 4.1 (on a 5point scale ranging from 1 - not at all important, to 5 - totally important), followed by adventure (looking for new experiences/adventure 
Table 3. Motivations for the practice of nature sports.

\begin{tabular}{|c|c|c|c|c|c|c|}
\hline \multirow[b]{2}{*}{ Nature sports motivations } & 1 & 2 & 3 & 4 & 5 & \multirow[b]{2}{*}{ Mean } \\
\hline & $\begin{array}{l}\text { Not at all } \\
\text { important }\end{array}$ & $\begin{array}{l}\text { Little } \\
\text { important }\end{array}$ & Important & $\begin{array}{c}\text { Very } \\
\text { important }\end{array}$ & $\begin{array}{l}\text { Totally } \\
\text { important }\end{array}$ & \\
\hline $\begin{array}{l}\text { Nature (to be in contact with nature; to } \\
\text { enjoy nature and the landscape; to protect } \\
\text { the environment) }\end{array}$ & $0.6 \%$ & $2.6 \%$ & $20.6 \%$ & $36.5 \%$ & $39.7 \%$ & 4.1 \\
\hline $\begin{array}{l}\text { Adventure (looking for new } \\
\text { experiences/adventure sensations; to } \\
\text { challenge and test oneself) }\end{array}$ & $1.2 \%$ & $6.5 \%$ & $26.0 \%$ & $38.8 \%$ & $27.5 \%$ & 3.9 \\
\hline $\begin{array}{l}\text { Sociability (to occupy free time; to interact } \\
\text { with other people/social contact; } \\
\text { conviviality provided by social contact) }\end{array}$ & $0.4 \%$ & $7.6 \%$ & $30.9 \%$ & $42.8 \%$ & $18.3 \%$ & 3.7 \\
\hline $\begin{array}{l}\text { Hygienism (following medical advice/health } \\
\text { reasons; to maintain and/or improve } \\
\text { physical condition; to relax/break with daily } \\
\text { routine) }\end{array}$ & $4.5 \%$ & $11.6 \%$ & $37.2 \%$ & $30.9 \%$ & $15.8 \%$ & 3.4 \\
\hline $\begin{array}{l}\text { Competition (to be involved in a sports } \\
\text { competition) }\end{array}$ & $33.0 \%$ & $35.5 \%$ & $18.7 \%$ & $8.4 \%$ & $4.3 \%$ & 2.2 \\
\hline $\begin{array}{l}\text { Tourism (to visit other sites/destinations; to } \\
\text { learn about other traditions and cultures; } \\
\text { to visit and help protect the heritage) }\end{array}$ & $2.0 \%$ & $10.7 \%$ & $29.7 \%$ & $36.3 \%$ & $21.4 \%$ & 3.6 \\
\hline
\end{tabular}

sensations; to challenge and test oneself), with an average of 3.9 points (see Table 3 ). Sociability (to occupy free time; to interact with other people/social contact; conviviality provided by social contact), hygienism (following medical advice/for health reason; to maintain and/or improve physical condition; to relax/break with dayly routine) and tourism (to visit other sites/destinations; to learn about other traditions and cultures; to visit and help protect the heritage) are also important reasons for the practice of nature sports with an average of 3.7, 3.6 and 3.4 points respectively). However, of the six highlighted reasons for the practice of nature sports, competition (to be involved in a sports competition) is the least important with an average of 2.2 points.

Comparing the motivation for the practice of nature sports by sex denotes some statistically significant differences, verifying that competition ( $p$-value $<0.100$ ) is more important for men than for women, while hygienism ( $p$ value $<0.050$ ) is more important for women than for men. There are no statistically significant differences in the remaining reasons.

Statistically significant differences were also found regarding age, denoting that the reasons associated with nature $(p$-value $<0.100)$ are more important for the group aged between 31 43 years (average of 4.3 points). Adventure ( $p$ value $<0.050)$ is more important for the youngest age group (18-30 years), while for the two older age groups this reason is less important. Competition ( $p$-value $<0.100$ ) is also more important for the youngest group (18-30 years). In term of sociability, hygienism and tourism, there are no statistically significant differences between each group. 
Considering the nine nature sports activities which were obtained more answers (see Figure 2 ), nature is the most important reason for the practice of nature sports, followed by adventure. For bodyboarders and surfers these two reasons (nature and adventure) are considered equally important (a mean of 4.2 points for both the reasons and both activities). Sociability is more important for kayaking participants (a mean of 4.0 points), while health issues (hygienism) are more relevant in MTB (mean of 3.6 points) and hiking (a mean of 3.5 points). Orienteering participants who practice mostly in a sports club are those with the highest mean for the reason of competition (a mean of 3.1 points). Reasons related to tourism are more important for mountaineering participants (a mean of 4.0 points) and trekking (a mean of 3.9 points).

Constraints for the practice of nature sports Considering the constraints for the practice of nature sports (Table 4), the most evident factor that prevents participants from practicing more frequently is lack of time (e.g. family and/or professional duties), with an average of 3.6 (on

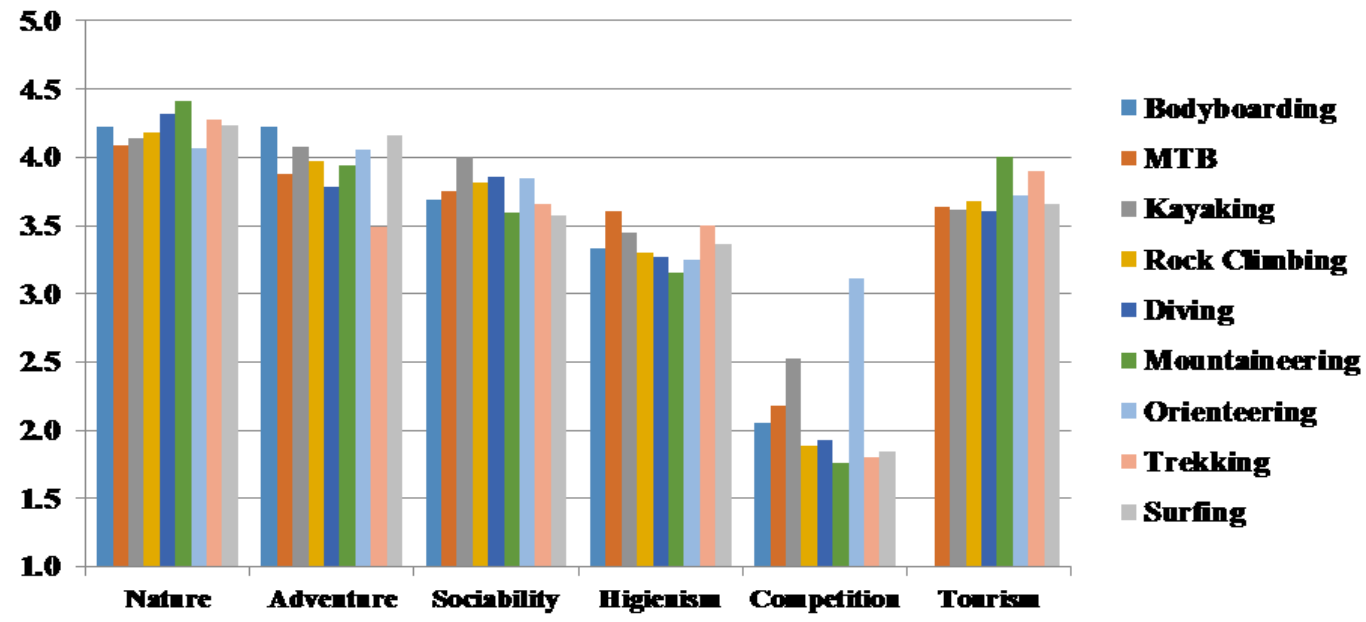

Figure 2. Mean values for the importance of practicing nature sports (measured on a 5-point scale ranging from 1 - not at all important, to 5 - totally important).

Table 4. Constraints for the practice of nature sports.

\begin{tabular}{lrrrrrr}
\hline \multirow{2}{*}{ Nature sports constraints } & \multicolumn{1}{c}{$\mathbf{1}$} & $\mathbf{2}$ & $\mathbf{3}$ & $\mathbf{4}$ & $\mathbf{5}$ & Mean \\
\cline { 2 - 6 } & $\begin{array}{c}\text { Not at all } \\
\text { important }\end{array}$ & $\begin{array}{c}\text { Little } \\
\text { important }\end{array}$ & Important & $\begin{array}{c}\text { Very } \\
\text { important }\end{array}$ & $\begin{array}{c}\text { Totally } \\
\text { important }\end{array}$ & Mean \\
\hline Because do not want & $54.5 \%$ & $25.8 \%$ & $11.1 \%$ & $4.3 \%$ & $4.3 \%$ & 1.8 \\
Lack of time & $4.3 \%$ & $9.8 \%$ & $31.5 \%$ & $33.8 \%$ & $20.7 \%$ & 3.6 \\
Lack of money & $16.3 \%$ & $24.9 \%$ & $32.3 \%$ & $17.0 \%$ & $9.5 \%$ & 2.8 \\
Seasonal activity & $31.0 \%$ & $32.4 \%$ & $23.4 \%$ & $9.8 \%$ & $3.5 \%$ & 2.2 \\
Away from the zone of & $27.0 \%$ & $27.4 \%$ & $27.3 \%$ & $13.2 \%$ & $5.2 \%$ & 2.4 \\
residence & $39.5 \%$ & $33.3 \%$ & $16.8 \%$ & $7.4 \%$ & $3.0 \%$ & 2.0 \\
Lack of transports & $45.3 \%$ & $25.0 \%$ & $14.4 \%$ & $8.1 \%$ & $7.2 \%$ & 2.1 \\
Health reasons & $26.7 \%$ & $30.2 \%$ & $28.1 \%$ & $10.4 \%$ & $4.6 \%$ & 2.4 \\
Lack of company & $34.1 \%$ & $29.5 \%$ & $21.6 \%$ & $9.1 \%$ & $5.8 \%$ & 2.2 \\
Lack of motivation & $35.4 \%$ & $29.7 \%$ & $22.3 \%$ & $8.4 \%$ & $4.2 \%$ & 2.2 \\
Bad conditions of the spaces & $37.0 \%$ & $27.4 \%$ & $19.6 \%$ & $10.3 \%$ & $5.7 \%$ & 2.2 \\
of the practice & $41.3 \%$ & $28.6 \%$ & $19.2 \%$ & $7.6 \%$ & $3.3 \%$ & 2.0 \\
Lack of equipment & & & & & & 125 \\
Lack of skills & & & & & & \\
\hline
\end{tabular}


a 5 points scale ranging from 1 - not at all important, to 5 - totally important), and lack of money, with an average of 2.8. Constraints considered as less important by participants are lack of transport and lack of knowledge, with an average of 2.0 in both factors.

Results show that women have higher (average) indexes in all factors when comparing the different types of constraints for the practice of nature sports by sex. In all age group, lack of time is the main limit factor to more regular practice, although less relevant to the group of over 56 years (mean 2.6). Data also show that younger individuals (18-30 years) present (perceive) a greater level of constraints in all items, compared to the other groups, with the exception of lack of time, which is most evidenced by the group aged between 31-43 years.

It is also relevant to consider the differences by marital status and working situation. It is denoted that time is not a constraint which is important for divorced/separated or widowed individuals (a mean of 3.3), whereas it is more important for married/ living with partner (a mean of 3.7) than it is for single (a mean of 3.5) individuals. On the other hand, the finance is a more important constraint for single individuals (average of 2.9), and a less important factor for divorced/separated or widowed individuals (average of 2.5). It appears that the working situation presents participants with larger time constraints but smaller financial constraints than others.

In considering the nine nature sports activities which obtained more answers (see Figure 3), it is verified that lack of time is the main factor pointed to by participants of all activities. Lack of money is as important as the lack of time (average of 3.7 in both) for divers, probably because of the high costs that are associated with this practice. The effect of seasonality is found to be more important in kayaking and diving activities (average of 2.5 for both), although this is not a very important factor for the participants of those activities. The fact that places of practice are away from the place of residence represents a major constraint for climbers and divers (average of 2.7 in both), while health reasons are more important for orienteering participants (average of 2.5). For rock-climbers, lack of company is the second major constraint, which can be explained by the fact that this activity requires at least two people for practice to conform to the necessary safety processes. Lack of motivation is also more important for climbers (a mean of 2.4). Bad conditions at the places of practice are more important for divers and surfers (average of 2.5 in both), while lack of equipment is more important for kayaking and rock-climbing (average of 2.5 in both), while a lack of knowledge is more important for rock-climbing and surfing (average of 2.3 for both).

These results are consistent with other studies showing that there are a number of barriers to participation that are common in all populations and activities (Holland, Pennington-Gray, \& Thapa, 2001; Scott \& Kim, 1998; Virden \& Yoshioka, 1992) such as lack of time, lack of money, personal health, and the lack of company. In this case, because the study only considered those who are participants of nature sports, and who therefore already active individuals, personal health is not a constraint that is as important.

\section{Discussion and conclusions}

This work presents a general description of the participants' socio-demographic characteristics, demand profile, practice behaviour, motivations and constraints for the nature sports practice, something which had not yet been examined in Portugal. Results from this work show some asymmetries in nature sports participation. Data point to greater male participation, which is consistent with the predominant male participation in nature sports in other countries (e.g., Betrán \& Betrán, 1998). This evidence is also emphasized by participation in physical sporting activities in the European Union (European Commission, 2014), indicating that men have a higher rate of participation comparing with women, especially in the countries of southern Europe. Most female participants are single, while for men there is a clear equality between married/living with partner and single individuals. This data suggests that the traditional division of roles in the domestic context, dominated by patriarchy, continue to limit the leisure activities of women. Indeed, unmarried and childless women are 

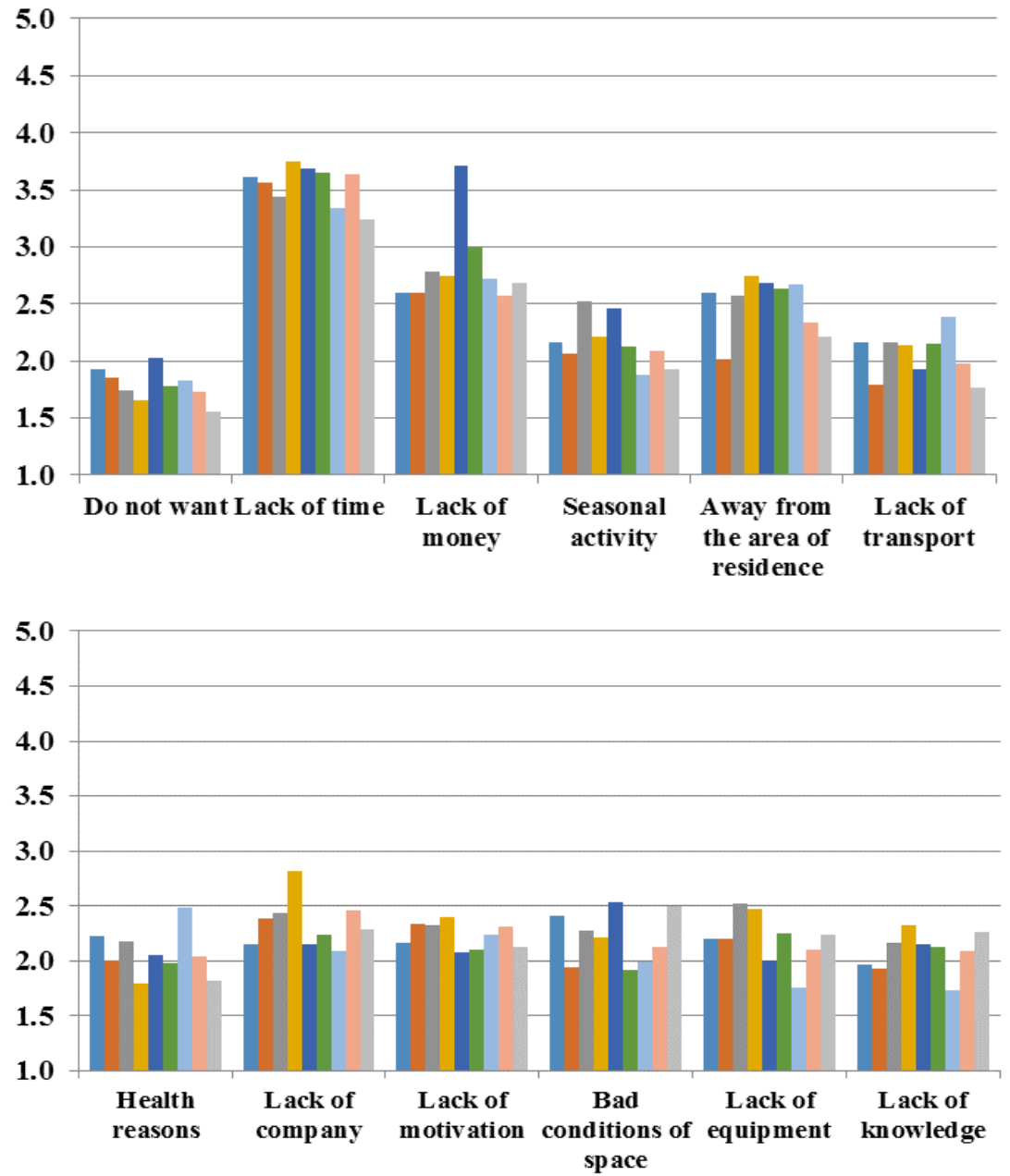

- Bodyb oarding

MTB

Kayaking

- Rock Climbing

Diving

Mountain eering

Orienteering

Trekking

Surfing

Bodyboarding

MTB

Kayaking

Rock Climbing

- Diving

Mountain eering

Orienteering

Trekking

Surfing

Figure 3. Mean values of the importance of the constraints to practicing nature sports (measured on a 5-point scale ranging from 1 - not at all important, to 5 - totally important).

practicing more nature sports. This is in accordance with the data obtained in other studies (European Commission, 2014), showing that after marital commitments and having dependent children, women present lower rates of participation in physical activity and sports, including nature sports. Further, this is in line with participation being primarily youthful, and with the number of respondents decreasing with advancing age, which therefore assumes a decrease in participation with the age. This has also been demonstrated in other studies on these activities (Betrán \& Betrán, 1998). In addition, the education of the sampled individuals is highlighted: they are highly qualified engaged in highly skilled jobs, bringing a correspondingly higher level of income, compared to the national average. This shows asymmetries in nature sports participation in terms of cultural, social and economic capital. As a result, data from this study are consistent with those presented by Pociello (1981), who named this phenomenon of using natural energy sources via ecological apparatus (bicycles, surfboards, hang-gliding, etc.), characteristic of individuals in possessing of overall high capital (particularly cultural capital) as the "ecologization of the sport practices". Results also show a higher response rate in the country's main coastal districts, possibly related to regional demographic asymmetries of Portugal, and the 
differences in the spread of sporting activities in the territory. The general profile of nature sports participants thus corresponds to the male individual, young, single, with a high level of education, working for others in a highly qualified job, with economic capital above the national average, and resident at the country's coast.

Data also point to a satisfied demand for the practice of nature sports, although the relationship between satisfaction and frequency fall short of the desired level, since most nature sports participants would like to develop their favourite activity more often, therefore assuming some constraints that affect the frequency of practice. Demand data highlights that MTB is simultaneously the activity that was performed by more nature sports participants (at least once), the activity practiced more often by the largest number of individuals, and the activity that individuals would like to practice more often. On the other hand, mountaineering, scuba diving and kayaking are activities that have great potential demand. Analysis by sex demonstrates a differentiated participation by male/female sex, showing that nature sports (tourism) is a space which reproduces traditional male culture. According to traditional culture, to men corresponds to the practice of vigorous, energetic and risk-taking based sports that allow them to emphasize their power, domination and masculinity. On the other hand, women have a lower participation in vigorous activities, and a higher concentration in informational and contemplative activities, particularly trekking, incorporating a greater identification with the female condition. Results also show a transition from the practice of activities with higher technical, physical and energetic requirements to more informational and contemplative activities, demonstrating a changing profile of participation with advancing age. As previously referred to by Neto (1997), these data suggest that practicing more demanding activities is a phenomenon of those who are younger, due to their physical, emotional and psychosocial development. This shows a search for excitement, pleasure, physical adventure, and new sensations, more focused on exploring one's own physical limits in confrontation with the natural physical space. With advancing age, and with decreasing in physical strength there is a trend for decrease participation in the more energetic activities, and a transference into activities that are less physically demanding and which present a lower risk of bodily harm. These tend to be focused on nature and the contemplation of the landscape, and accommodate a greater cultural, aesthetic and touristic investment in the activities (Pociello, 1995).

Despite having many features in common, the different typologies of nature sports activities show differences in practice behaviour. This gives each of them a very individual profile, depending on the characteristics of each type of activity (location of spaces, socioorganizational level), as well as the sociodemographic characteristics of its participants. Results of this study show that the location of practices influence the profile of participation, demonstrating a tendency for the activities that take place near the area of residence to be practiced with more regularity and frequency, though for a shorter duration, evidenced by the practice profiles of MTB, bodyboarding and surfing. On the other hand, activities which require more travelling are practiced with less regularity and frequency, but for a longer duration, such as the case of mountaineering and scuba diving. The socio-organizational context also influences the profile of participation, since the practices carried out in sports clubs are undertaken more frequently and regularly, while the practices carried out in an informal context (e.g., through a tourism company) are practiced with less regularity and frequency as shown in the case of canyoning. The different socio-demographic characteristics of participants also shows differences in the profile of participation for the various nature sports activities. Young people, students, single people and those without children have an increased regularity and frequency of practice in the various nature sports activities. This is because they have greater freedom, and a greater possibility of managing their time. On the other hand, individuals who are active in work and have a family and children tend to practice less regularly and frequently because of greater time constraints. 
Nature (e.g., to stay in contact with nature) and adventure (e.g., to have new experiences and adventurous sensations) are the main reasons for practicing nature sports. On the other hand, the reasons that are classified at lower rates by respondents overall, were associated with competition, which demonstrates the playful character of the nature sports practices. However, the activities within sports clubs (formal sport) have a higher competitive motivation (e.g., orienteering). Sociability (to occupy free time, to interact with other people/social contact, and the conviviality provided by social contact) is more important for kayakers. Health reasons (hygienism) are more relevant for mountain bikers and trekkers, while tourism is more important for mountaineers and trekkers. Results concerning motivation by sex and age highlight that competition is more important for men than for women, while hygienism is more important for women than for men. Adventure and competition is more important for the younger age group, while nature is more important for older age groups.

With regard to the constraints indicated for the practice of nature sports, participants state that lack of time is the primary factor, followed by financial constraints, as already reported in other studies (Scott \& Kim, 1998; Walker \& Virden, 2005). On the other hand, lack of transport and lack of technical knowledge are stated as less important factors. Overall, women perceive higher levels of constraints than men do, in all proposed items. Again, this has already been demonstrated in other studies (Henderson \& Dialeschkia, 1991; Henderson \& Hickerson, 2007; Johnson et al., 2001). In this regard, Rojek (1985) states that women experience a unique set of barriers that are not evident for men, and which relate both to the structure of the sexual role imposed on women and the concerns that they present as sex objects in a male-dominated patriarchal society. In this sense, women tend to deny the opportunity to engage in such activities (and other types of leisure), because of family responsibilities, and particularly because of having the role of caregivers. Lack of time is also the constraint most cited by participants who are active workers and married. On the other hand, for the younger group and for students, the financial constraints are the most important, because they are at a stage of life where they do not work and therefore do not have money, despite having the time to practice nature sports. These data indicate a high valuation on time and money variables in the practice of nature sports. This is especially relevant for the socio-demographic characteristics of the participants. Similarly, constraints also depend on the activity in question. For example, in scuba diving, which is a more expensive practice and developed outside of the area of residence, financial and time constraints are equal (and classified with an equal level of importance). However, the frequency with which other activities are practices is principally constrained by the time available.

These results present some recommendations for nature sports managers and for the development of policies for this sector. This data and a further segmentation of participants allows organizations to develop marketing strategies, depending on the profile of their target group, and to adjust their nature sports supply, as suggested by Chazaud (2004). To achieve a greater penetration in the Portuguese population (equivalent to the France level, for example), it is important to develop a differentiated and articulated offer among all sectors of nature sports (associative, local government, education, business, federated, etc.), which can fit into all segments of the population, in order to eliminate the asymmetries highlighted in this work.

This study also presents some limitations. The first is associated with the theoretical and methodological limitations of the survey questionnaire, particularly in terms of the (online) application form, despite the temporal and financial benefits. Secondly, the absence of data on the total number of nature sports participants can expose a limitation in the representativeness of the sample. Finally, the sample size, especially the low response rate in some activities (practiced more often) prevents further analysis of the participants of these activities. Despite these limitations, thought, the similarity of the overall results when compared to other studies (e.g., Betrán \& Betrán, 1998; Pociello, 1981), allows for the 
extrapolation of some evidences, particularly in participation asymmetries resulting from sociodemographic characteristics (in relation to sex, age, and economic and cultural capital), but also in the apparent irregularity and low frequency of participation in certain nature sports activities.

\section{Funding}

This publication was supported by the Portuguese Foundation for Science and Technology (Fundação para a Ciência e a Tecnologia) under the strategic project: UID/SOC/50012/2013.

\section{References}

Balmford, A., Beresford, J., Green, J., Naidoo, R., Walpole, M., \& Manica, A. (2009). A global perspective on trends in naturebased tourism. PLoS biology, 7(6).

Barbieri, C., \& Sotomayor, S. (2013). Surf Travel Behavior and Destination Preferences: An Application of the Serious Leisure Inventory and Measure. Tourism Management, 35, 111-121.

Barić, D., Anić, P., \& Macias Bedoya, A. (2016) Segmenting protected area visitors by activities: A case study in Paklenica National Park, Croatia. European Journal of Tourism Research, 13, 103-121

Bartram, S. (2001). Serious Leisure Careers among Whitewater Kayakers: A Feminist Perspective. World Leisure Journal, 43(2), 4-11.

Beedie, P. (2007). Legislators and Interpreters: An Examination of Changes. In $M$. McNamee (Ed.), Philosophical Risk and Adventure Sports (pp. 25-42). London: Routledge.

Bell, S., Tyrvainen, L., Sievanen, T., Prbstl, U., \& Simpson, M. (2007). Outdoor Recreation and Nature Tourism: A European Perspective. Living Reviews in Landscape Research, 1, 1-46.

Bessy, O., \& Mouton, M. (2004). Du plein air au sport de nature. Nouvelles pratiques, nouveaux enjeux. Cahier Espaces: Sports de nature. Évolutions de l'offre et de la demande, 81, 13-29.

Betrán, A., \& Betrán, J. (1998). Análisis de la demanda potencial de las actividades físicas de aventura en la naturaleza en la ciudad de Barcelona. Apunts: Educatión Física y Deportes, 52, 92-102.

Bouter, L., Knipschild, P., Feij, J., \& Volovics, A. (1988). Sensation seeking and injury risk in downhill skiing. Personality and Individual Differences, 9(3), 667-673.

Breivik, G. (2010). Trends in adventure sports in a postmodern society. Sport in Society, 13(2), 260-273.

Buckley, R. (2012). Rush as a Key Motivation in Skilled Adventure Tourism: Resolving the Risk Recreation Paradox. Tourism Management, 33, 961-970.

Burch, W. (1969). The Social Circles of Leisure: Competing Explanations. Journal of Leisure Research, 1(2), 125-147.

Carvalhinho, L. (2006). Os Técnicos e as Actividades de Desporto de Natureza Análise da Formação, Funções e Competências Profissionais (Unpublished doctoral dissertation). UTAD, Vila Real, Portugal.

Celsi, R. (1992). Transcendent Benefits of High-Risk Sports. In J. Sterntha \& S. Brian (Eds.), Advances in Consumer Research (pp. 636-641). Provo: Association for Consumer Research.

Centre for Responsible Travel (2015). The Case for Responsible Travel: Trends \& Statistics 2015. Retrieved from: https://ecotourism.app.box.com/s/rxiyp6574 4sqilmrybfk8mys3qvjbe9g [Accessed 05 May 2015].

Chang, H, \& Huang, Y. (2012). Paragliding Adventure Recreation Consumers' Activity Motivation, Enduring Involvement and Their Involved Behavior. The Journal of International Management Studies, 7(2), 61-74.

Chazaud, P. (2004). Management du tourisme et des loisirs sportifs de pleine nature. Voiron: Editions PUS.

Cheng, T-M., \& Tsaur, S-H. (2012). The Relationship between Serious Leisure Characteristics and Recreation Involvement: A Case Study of Taiwan's Surfing Activities. Leisure Studies, 31(1), 53-68.

Cordell, H., McDonald, L., Teasley, R., Bergstrom, J., Martin, J., Bason, J., \& Leeworthy, V. (1999) Outdoor Recreation Participation Trends. In H. Cordell, C. Betz, J. Bowker et al. (Eds.), Outdoor Recreation in American Life: A National Assessment of 
Demand and Supply Trends (pp. 219-231). Champaign: Sagamore Publishing.

Corneloup, J. (2005). La place du marché dans le fonctionnement des loisirs sportifs de nature. Téoros, 24(1), 55-61. Retrieved from http://teoros.revues.org/1528.

Crawford, D., \& Godbey, G. (1987). Reconceptualizing barriers to family leisure. Leisure Sciences, 9(1), 119-127.

Crawford, D., Jackson, E., \& Godbey, G. (1991). A hierarchical model of leisure constraints. Leisure Sciences, 13, 309-320.

Crosset, T., \& Beal, B. (1997). The Use of "Subculture" and "Subworld" in Ethnographic Works on Sport: a Discussion of Definitional Distinctions. Sociology of Sport Journal, 14, 73-85.

Csikszentmihalyi, M. (1975). Beyond Boredom and Anxiety: Experiencing Flow in Work and Play. San Francisco: Jossey-Bass.

De Knop, P. (1990). Sport for all and active tourism. World Leisure and Recreation, 32, 30-36.

DECO. (2008). Guia dos Desportos de Natureza. Lisboa: DECO.

Dilley, R., \& Scraton, S. (2010): Women, Climbing and Serious Leisure. Leisure Studies, 29(2), 125-141.

Driver, B., \& Brown, P. (1978). The Opportunity Spectrum Concept and Behavioral Information in Outdoor Recreation Resource Supply Inventories: A Rationale. In H. Lund et al. (Eds.), Integrated Inventories of Renewable Natural Resources: Proceedings of the Workshop (pp. 24-31). Tucson: USDA Forest Service, General Technical Report.

Driver, B., \& Knopf, R. (1976). Temporary Escape: One Product of Sport Fisheries Management. Fisheries, 1(2), 21-29.

Driver, B., \& Tocher, R. (1970). Toward a Behavioral Interpretation of Recreational Engagements with Implications for Planning. In B. Driver (Ed.), Elements of Outdoor Recreation Planning (pp. 9-31). Ann Arbor, $\mathrm{Ml}$ : University Microfilms.

Driver, B. (1977). Item Pool for Scales Designed to Quantify the Psychological Outcomes Desired and Expected from Recreation Participation. Ft. Collins, CO: USDA Forest Service Rocky Mountain Forest and Range Experiment Station.
Elkington, S., \& Stebbins, R. (2014). The Serious Leisure Perspective: An Introduction. Abingdon: Routledge

European Commission. (2014). Sport and physical activity. Special Eurobarometer 412/Wave 80.2. D-G Education and Culture. Brussels.

Ewert, A., \& Hollenhorst, S. (1989). Testing the Adventure Model: Empirical Support for a Model of Risk Recreation Participation. Journal of Leisure Research, 20(3), 124139.

Ewert, A., \& Hollenhorst, S. (1994). Individual and Setting Attributes of the Adventure Recreation Experience. Leisure Sciences, 16(4), 177-191.

Falcão, A., Damásio, A., \& Melo, R. (2017). Profile of practice, travel behaviour and motivations for geocaching. European Journal of Tourism Research, 16, 92-107.

Festau, D. (2002). Motivational factors that influence students' participation in outdoor activities. Journal of Adventure Education and Outdoor Learning, 2(1), 43-54.

Flucker, M., \& Turner, L. (2000). Needs, Motivations, and Expectations of a Commercial Whitewater Rafting Experience. Journal of Travel Research, 38(4), 380-389.

Gammon, S., \& Robbinson, T. (1997). Sport and Tourism: A Conceptual Framework. Journal of Sport Tourism, 4(3), 8-24.

Gammon, S. (2015). Sport Tourism. Finding its place?. In S. Gammon \& R. Elkington (Eds.), Landscapes of Leisure. Space, Place and Identity (pp. 110-122). London \& New York: Palgrave Macmillan.

Getz, D., \& McConnell, A. (2011). Serious Sport Tourism and Event Travel Careers. Journal of Sport Management, 25, 326-339.

Gibson, H. (1998a). Active Sport Tourism: Who Participates? Leisure Studies, 17(2), 155170.

Gibson, H. (1998b). Sport Tourism: A Critical Analysis of Research. Sport Management Review, 1, 45-76.

Gibson, H. (2002). Sport Tourism at a Crossroad? Considerations for the Future. In S. Gammon \& J. Kurtzman (Eds.), Sport Tourism: Principles and Practice (pp. 123140). Eastbourne: Leisure Studies Association. 
Gibson, H. (2004). Moving Beyond the 'What is and Who' of Sport Tourism to Understanding 'Why'. Journal of Sport Tourism, 9(3), 247-265.

Goodale, L., \& Witt, A. (1998). Recreation NonParticipation and Barriers to Leisure. In E. Jackson \& L. Burton (Eds.), Understanding Leisure and Recreation: Mapping the Past, Charting the Future (pp. 421-449). State College: Venture Publishing.

Hall, C., \& Page, S. (2006). The Geography of tourism and Recreation. Environment, place and space (3rd ed.). London: Routledge.

Weiler, B., \& Hall, M. (1992). Special Interest Tourism. London: Belhaven Press.

Hall, C. (1992). Adventure, Sport and Health Tourism. In B. Weiler \& C. Hall (Eds.), Special Interest Tourism (pp. 141-158). London: Bellhaven Press.

Hendee, J. (1974). A Multiple-Satisfaction Approach to Game Management. Wildlife Society Bulletin, 2(3), 104-113.

Henderson, K., \& Dialeschkia, M. (1991). A Sense of Entitlement to Leisure as constraint and Empowerment for Women. Leisure Sciences, 13, 51-65.

Henderson, K., \& Hickerson, B. (2007). Women and Leisure: Premises and Performances Uncovered in an Integrative Review. Journal of Leisure Research, 39(4), 591-610.

Henderson, K., Bedini, L., Hecht, L., \& Schuler, R. (1995). Women with Physical Disabilities and the Negotiation of Leisure Constraints. Leisure Studies, 14, 17-31.

Hennigs, B., \& Hallmann, K. (2014). A motivation-based segmentation study of kitesurfers and windsurfers. Managing Sport and Leisure, 20(2), 117-134.

Higham, J., \& Hinch, T. (2009). Sport and Tourism: Globalization, Mobility and Identity. Oxford: Elsevier.

Hinch, T., \& Higham, J. (2004). Sport Tourism Development. Clevedon: Channel View Publications.

Hinch, T., Jackson, E., Hudson, S., \& Walker, G. (2005). Leisure Constraint Theory and Sport Tourism. Sport in Society, 8(2), 142163.

Hubbard, J., \& Mannell, R. (2001). Testing Competing Models of the Leisure Constraint Negotiation Process in a Corporate Employee Recreation Setting. Leisure Sciences, 23(3), 145-163.
Illundáin-Aguruzza, J. (2007). Kant Goes Skydiving: Understanding the Extreme by Way of the Sublime. In M. McNamee (Ed.), Philosophy, Risk and Adventure Sports (pp. 149-167). London: Routledge.

Instituto Nacional de Estatística. (2011a). Censos 2011 - Resultados Finais. Lisboa: Instituto Nacional de Estatística.

Instituto Nacional de Estatística. (2013). Rendimento médio mensal líquido (Série 2011 - €) da população empregada por conta de outrem por local de residência (NUTS - 2002) e Profissão; Trimestral - INE, Inquérito ao Emprego. Lisboa: Instituto Nacional de Estatística.

Iso-Ahola, S., \& Graefe, A. (1988). Perceived competence as a mediator of the relationship between high risk sports participation and self-esteem. Journal of Leisure Research, 21(1), 32-39.

Jack, S., \& Ronan, K. (1998). Sensation seeking among high and low risk sports participants. Personality and Individual Differences, 25(6), 1063-1083.

Jackson, E., \& Henderson, K. (1995). Genderbased analysis of leisure constraints. Leisure Sciences, 17(1), 31-51.

Jackson, E., \& Scott, D. (1999). Constraints on leisure and recreation. In E. Jackson, \& $T$. Burton (Edits.), Leisure studies: Prospects for the twenty-first century (pp. 299-321). State College, PA: Venture Publishing.

Jackson, E. (1988). Leisure constraints: a survey of past research. Leisure Sciences, 10(3), 203-215.

Jackson, G., \& Weed, M. (2003). The Sport Tourism Interrelationship. In B. Houlihan (Ed.), Sport in Society (pp. 235-251). London: Sage Publications.

Jackson, E. (2005). Leisure Constraints Research: Overview of a Developing theme in Leisure Studies. In E. Jackson (Ed.), Constraints to Leisure (pp. 3-19). State College: Venture Publishing.

Jackson, E., Crawford, D., \& Godbey, G. (1993). Negotiation of leisure constraints. Leisure Sciences, 15(1), 1-11.

Johnson, C., Bowker, J., \& Cordell, H. (2001). Outdoor Recreation Constraints: An Examination of Race, Gender, and Rural Dwelling. Southern Rural sociology, 17, 111-133. 
Kane, M., \& Zink, R. (2004). Package adventure tours: markers in serious leisure career. Leisure Studies, 23(4), 329-345.

Krein, K. (2008). Sport, Nature and Worldmaking. Sport, Ethics and Philosophy, 2(3), 285-301.

Krein, K. (2014). Nature Sports. Journal of the Philosophy of Sport, 41(2), 193-208.

Krein, K. (2015). Reflections on Competition and Nature Sports. Sport, Ethics and Philosophy, 9(3), 271-286.

Kusz, K. (2004). Extreme America: the Cultural Politics of Extreme Sports in 1990s America. In B. Wheaton (Ed.), Understanding Lifestyle Sports Consumption, Identity and Difference (pp. 197-213). London: Routledge.

Langseth, T. (2011). Risk Sports - Social Constraints and Cultural Imperatives. Sport in Society, 14(5), 629-644.

Le Breton, D. (2000). Passions du Risque. Paris: Métailié.

Lewis, N. (2004). Sustainable Adventure: Embodied Experiences and Ecological Practices within British Climbing. In B. Wheaton (Ed.), Understanding Lifestyle Sports - Consumption, Identity and Difference (pp. 70-93). London: Routledge.

Loucks-Atkinson, A., \& Mannell, R. (2007). Role of Self-Efficacy in the Constraints Negotiation Process: The Case of Individuals with Fibromyalgia Syndrome. Leisure Sciences, 29, 19-36.

Lyng, S. (Ed.) (2005). Edgework: The Sociology of Risk-Taking. New York: Routledge.

Manfredo, M., Driver, B., \& Tarrant, M. (1996). Measuring Leisure Motivation: A MetaAnalysis of the Recreation Experience Preference Scales. Journal of Leisure Research, 28(3), 188-213.

Mannell, R., \& Loucks-Atkinson, A. (2005). Why Don't People do What's Good for Them? Crossfertilization among the Psychologies of Nonparticipation in Leisure, Health and Exercise Behaviors. In E. Jackson (Ed.), Constraints to Leisure (pp. 221-232). State College: Venture Publishing.

Daniels, M., \& Norman, W. (2005). Motivations of equestrian tourists: an analysis of the colonial cup races. Journal of Sport Tourism, 10, 201-210
Markides, K., Liang, J., \& Jackson, J. (1990). Race, Ethnicity, and Aging: Conceptual and Methodological Issues. In R. Binstock \& L. George (Eds.), Handbook of Aging and the Social Sciences (pp. 112-129). San Diego: Academic Press.

Marôco, J. (2010). Análise Estatística com o PASW Statistics (ex-SPSS). Lisboa: Report Number.

Marques, C., Reis, E., \& Menezes, J. (2010). Profiling the segments of visitors to Portuguese protected areas. Journal of Sustainable Tourism, 18(8), 971-996.

Martin, R., \& Martin, J. (2001). Culturas Deportivas y Valores Sociales: Una Aproximación a la Dimensión Social del Deporte. Apunts: Educación Física $y$ Deportes, 64, 33-45.

Mclntyre, N. (1992). Involvement in Risk Recreation: A Comparison of Objective and Subjective Measures of Engagement. Journal of Leisure Research, 24(1), 64-71.

Mehmetoglu, M. (2007). Typologising nature based tourists by activity-theoretical and practical implications. Tourism Management, 28, 651-660.

Melo, R. (2017). Understanding Nature Sports Tourism Participation: A Literature Review. In R. Melo \& C. Sobry (Eds.), Sport Tourism: New Challenges in a Globalized World (pp. 241-275). Cambridge: Cambridge Scholars Publishing.

Melo, R., \& Gomes, R. (2016a). Nature Sports and Sustainable Local Development: Practitioners and Organizations Managers' Perspectives in Portugal. In C. Sobry (Ed.), Sport Tourism and Local Sustainable Development (pp. 75-100). Lille: L'Harmattan.

Melo, R., \& Gomes, R. (2016b). Understanding Nature Sports Organizations in Portugal. The Open Sports Sciences Journal, 9, 13-25.

Melo, R., \& Gomes, R. (2017). A Sociocultural Approach to Understand the Development of Nature Sports. In R. Melo \& C. Sobry (Eds.), Sport Tourism: New Challenges in a Globalized World (pp. 60-90). Cambridge: Cambridge Scholars Publishing.

Ministério das Cidades Ordenamento do Território e Ambiente. (2003). Decreto Regulamentar n. ${ }^{\circ}$ 18/99, Alterado pelo Decreto Regulamentar n. ${ }^{\circ} 17 / 2003$, de 10 
de Outubro. Diário da República, I Série $B(235), 6688-6689$.

Mitchell, R. (1983). Mountain Experience: The Psychology and Sociology of Adventure. Chicago: University of Chicago Press.

Neto, C. (1997). Mudanças sociais, desporto e desenvolvimento humano. In A. Correia (Ed.), O Desporto em Portugal: opções e estratégias de desenvolvimento. Actas do II Congresso de Gestão do Desporto (pp. 2534). Lisboa: Associação Portuguesa de Gestão do Desporto.

O'Connell, T. (2010). The Effects of Age, Gender and Level of Experience on Motivation to Sea Kayak. Journal of Adventure Education and Outdoor Learning, 10(1), 51-66.

Page, S., \& Dowling, R. (2002). Ecotourism. Essex: Prentice Hall

Palmer, C. (2004). Death, Danger and the Selling of Risk in Adventure Sports. In B. Wheaton (Ed.), Understanding Lifestyle Sports - Consumption, Identity and Difference (pp. 55-69). London: Routledge.

Pereira, A. (2009). Sport and Risk: The Case of High-Altitude Climbing. European Journal for Sport and Society, 6(2), 163-178.

Pestana, M., \& Gageiro, J. (2003). Análise de dados para ciências sociais: a complementaridade do SPSS. Lisboa: Silabo.

Pigeassou, C. (2004). Contribution to the definition of sport tourism. Journal of Sport \& Tourism, 9(3), 287-289.

Pociello, C. (1981). La force, l'énergie, la grâce et les réflexes. Le jeu complexe des dispositions culturelles et sportives. In C. Pociello (Ed.), Sports et société (pp. 171237). Paris: Editions Vigot.

Pociello, C. (1995). Les Cultures Sportives. Paris: Editions «PUF».

Priest, S. (1990). The Adventure Experience Paradigm. In J. Miles \& S. Priest (Eds.), Adventure Education (pp. 157-162). State College: Venture Publishing.

Priest, S. (1992). Factor Exploration and Confirmation for the Dimensions of an Adventure. Journal of Leisure Research, 24, 127-139.

Priest, S., \& Gass, M. (1997). Effective Leadership in Adventure Programming. Champaign, IL: Human Kinetics.
Reeves, M. (2000). Evidencing the SportTourism Interrelationship (Unpublished Doctoral Dissertation). Loughborough University, Leicestershire, UK.

Reynolds, Z., \& Hritz, N. (2012): Surfing as Adventure Travel. Motivations and Lifestyles. Journal of Tourism Insights, 3(1), 1-18.

Roberts, G., \& Treasure, D. (Eds.) (2012). Advances in Motivation in Sport and Exercise. Champaign: Human Kinetics.

Robinson, D. (1985). Stress Seeking: Selected Behavioral Characteristics of Elite Rock Climbers. Journal of Sport Psychology, 7, 400-404.

Robinson, D. (1992). A Descriptive Model of Enduring Risk Recreation Involvement. Journal of Leisure Research, 24(1), 52-63.

Robinson, T. \& Gammon, S. (2004). A Question of Primary and Secondary Motives: Revisiting and Applying the Sport Tourism Framework. Journal of Sport Tourism, 9(3), 221-223.

Rojek, C. (1985). Capitalism and Leisure Theory. London: Tavistock Publications.

Ryan, C. (2002). The Tourist Experience: A New Introduction. London: Continuum.

Schreyer, R., \& Rogenbuck, J. (1978). The Influence of Experience Expectations on Crowding Perceptions and Social Psychological Carrying Capacities. Leisure Sciences, 1(4), 373-394.

Scott, D., \& Kim, C. (1998). Outdoor Recreation Participation and Barriers to Involvement. Report submitted to the Texas Parks and Wildlife Department.

Shaw, G., \& Williams, A. (2002). Critical Issues in Tourism: A Geographical Perspective. Oxford: Blackwell.

Shores, K., Scott, D., \& Floyd, M. (2007). Constraints to Outdoor Recreation: A Multiple Hierarchy Stratification Perspective. Leisure Sciences: An Interdisciplinary Journal, 29(3), 227-246.

Standeven, J., \& De Knop, P. (1999). Sport Tourism. Champaign: Human Kinetics.

Stebbins, R. (1982). Serious Leisure: A Conceptual Statement. The Pacific Sociological Review, 25, 251-272.

Stebbins, R. (2005b). Project-Based Leisure: Theoretical Neglect of a Common use of Free Time. Leisure Studies, 24(1), 1-11. 
Stebbins, R. (2007). Serious Leisure: A Perspective for Our Time. New Brunswick: AldineTransaction.

Stebbins, R. (2005a). Challenging Mountain Nature: Risk, Motive and Lifestyle in Three Hobbyist Sports. Calgary: Detselig.

Stranger, M. (1999). The Aesthetics of Risk: A Study of Surfing. International Review for the Sociology of Sport, 34(3), 265-276.

Stranger, M. (2011). Surfing Life: Surface, Substructure and the Commodification of the Sublime. Surrey: Ashgate Publishing.

Sugerman, D. (2001). Motivations of older adults to participate in outdoor adventure experiences. Journal of Adventure Education and Outdoor Learning, 1(2), 2134.

Swarbrooke, J., Beard, C., Leckie, S., \& Pomfret, G. (2003). Adventure Tourism: The New Frontier. London and New York: Routledge.

Tarrant, M., Bright, A., Smith, E., \& Cordell, H. (1999). Motivations, Attitudes, Preferences, and Satisfactions among Outdoor Recreationists. In H. Cordell, C. Betz, J. Bowker et al. (Eds.), Outdoor Recreation in American Life: A National Assessment of Demand and Supply Trends (pp. 403-431). Champaign, IL: Sagamore Publishing.

Trimpop, R., Kerr, J., \& Kirkaldy, B. (1998). Comparing Personality Constructs of RiskTaking Behaviour. Journal of Personality and Individual Differences, 26(2), 237-254.

Vester, H. (1987). Adventure as a Form of Leisure. Leisure Studies, 6(3), 237-249.
Virden, R., \& Walker, G. (1999). Ethnic/Racial and Gender Variations among Meanings Given to and Preferences for, the Natural Environment. Leisure Sciences, 21, 219239.

Walker, G., \& Virden, R. (2005). Constraints on Outdoor Recreation. In E. Jackson (Ed.), Constraints to Leisure (pp. 201-220). State College: Venture Publishing.

Watson, N. (2007). Nature and Transcendence: The Mystical and Sublime in Extreme Sports. In J. Parry, S. Robinson, N. Watson \& M. Nesti (Eds.), Sport and Spirituality: An Introduction (pp. 95-105). London \& New York: Routledge.

Weed, M., \& Bull, C. (2004). Sport Tourism: Participants, Policy and Providers. Oxford: Butterworth Heinemann.

Weed, M. (2006). Editorial: Understanding Sports Tourism Participation: Complexities and Diversity. Journal of Sport \& Tourism, 11(3-4), 95-199.

White, D. (2008). A Structural Model of Leisure Constraints Negotiation in Outdoor Recreation. Leisure Sciences: An Interdisciplinary Journal, 30(4), 342-359.

Woratschek, H., Hannich, F., \& Ritchie, B. (2007). Motivations of Sports Tourists: An Empirical Analysis in Several European Rock Climbing Regions. Retrieved from http://www.fiwi.uni-

bayreuth.de/de/download/WP 02-07.pdf

Zuckerman, M. (1979). Sensation Seeking. Beyond the Optimal Level of Arousal. Hillsdale: Erlbaum. 